MATEUS GUSTAVO CHUQUI

\title{
Efeito de ondas internas na produção fitoplanctônica da Plataforma Continental Sudeste do Brasil
}

\author{
”Dissertação apresentada ao Instituto \\ Oceanográfico da Universidade de São Paulo, \\ como parte dos requisitos para obtenção do \\ título de Mestre em Ciências, Programa de \\ Oceanografia, área de Oceanografia \\ Biológica”. \\ “Orientador: Prof. Dr. Frederico Pereira \\ Brandini”
}




\title{
UNIVERSIDADE DE SÃO PAULO
}

INSTITUTO OCEANOGRÁFICO

\section{Efeito de ondas internas na produção fitoplanctônica da Plataforma Continental Sudeste do Brasil}

\author{
Mateus Gustavo Chuqui
}

Dissertação de Mestrado apresentada ao Instituto Oceanográfico da Universidade de São Paulo, como parte dos requisitos para obtenção do grau de Mestre em Oceanografia

"Julgada em ________ por"

Prof. (a) Dr. (a)

Prof. (a) Dr. (a)

Prof. (a) Dr. (a)
Conceito

Conceito

Conceito 


\section{Agradecimentos}

Aos meus pais e familiares por todo amor, carinho e atenção que me deram ao longo de todo o caminho até aqui.

À Giulia Campos pelo companheirismo, amizade, amor e pela paciência comigo.

Ao meu orientador e amigo Frederico Brandini pela oportunidade, confiança e pelas longas conversas acolhedoras.

Ao Dr. Rüdiger Röttgers por me hospedar e me receber de portas abertas em sua casa e em seu laboratório, e pelo empréstimo do equipamento utilizado neste trabalho.

Aos funcionários do IOUSP que possibilitaram a execução do projeto, especialmente a tripulação do Alpha Delphini, seção de transporte, logística, secretaria de pós-graduação, toda CPG, funcionários do DOB e da biblioteca.

Ao Pedro Marone, Luan Michelazzo, Maira Van Prehn, Rafael Menezes, Miolo, Lívia e Martino por toda força no embarque.

À CAPES pela bolsa de estudos que possibilitou minha permanência na academia Aos meus amigos pelas conversas cientificas e momentos de descontração, especialmente a Túlia Martinez, Vadim Harlamov, Mayza Pompeu, João Felipe dos Santos, Gabriel Moiano, Ianco Rodrigues e todo o pessoal da Ancora. 


\section{Sumário}

Resumo

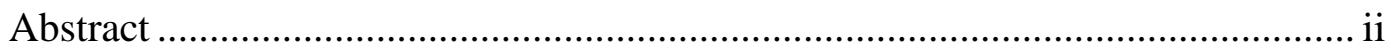

Índice de figuras ............................................................................................. iii

Índice de tabelas ........................................................................................... vi

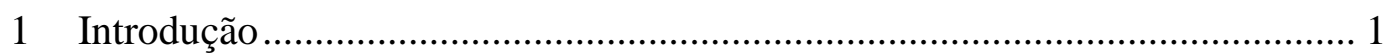

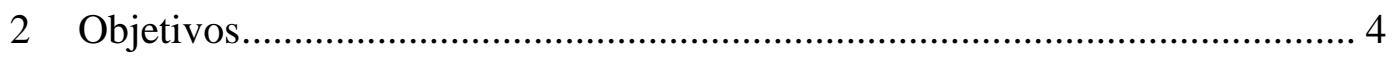

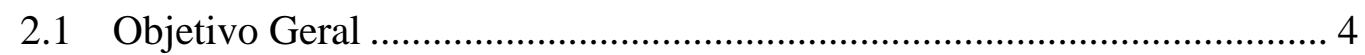

2.2 Objetivos Específicos ............................................................................. 4

3 Materiais e Métodos ……………………………………………………...... 5

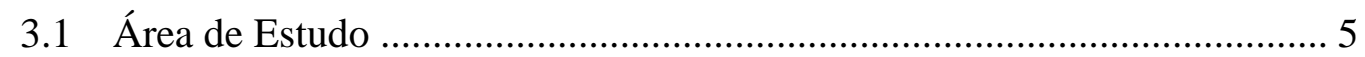

3.2 Aquisição de dados ................................................................................. 6

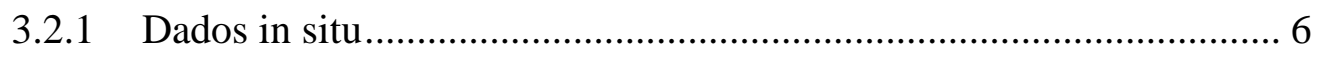

3.2.2 Nutrientes dissolvidos e Clorofila a ...................................................... 8

3.2.3 Citometria de Fluxo........................................................................ 8

3.2.4 Produtividade Primária........................................................................ 8

3.2.4.1 Medidas de taxas de transporte de elétrons ..................................... 8

3.2.4.2 Medidas das taxas de fotossíntese com a técnica de ${ }^{14} \mathrm{C}$............... 9

3.2.5 Dados complementares .................................................................... 9

3.2.5.1 Irradiância e nível do mar.............................................................. 9

3.2.5.2 Coeficiente de extinção de luz (k) .............................................. 10

3.2.5.3 Qualidade Espectral..................................................................... 10

3.2.6 Modelo de Produção Fitoplanctônica.................................................... 11

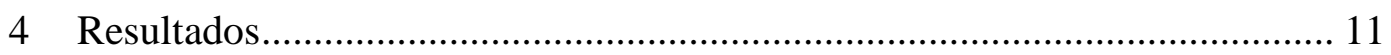

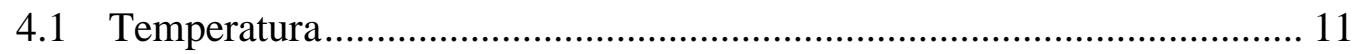




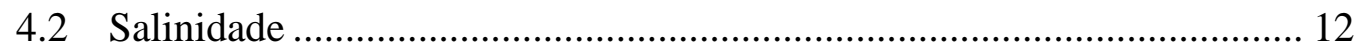

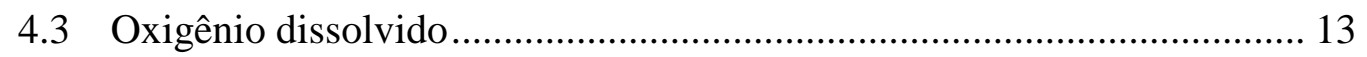

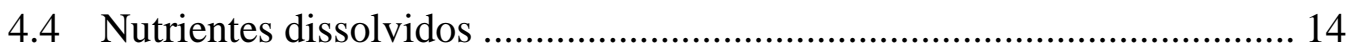

4.5 Clorofila-a e Citometria de Fluxo.............................................................. 16

4.6 Curvas de luz fotossíntese e parâmetros fotossintéticos......................... 19

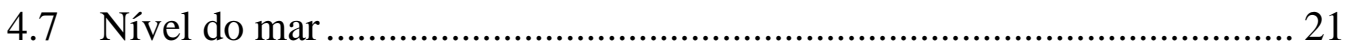

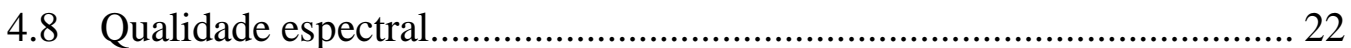

4.9 Irradiância incidente ........................................................................... 22

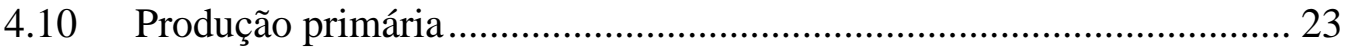

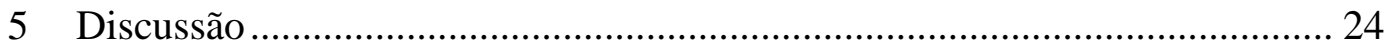

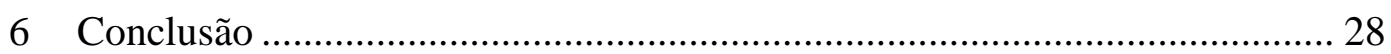

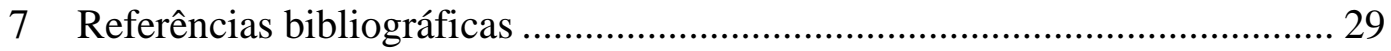




\section{Resumo}

Este trabalho visa avaliar o efeito do movimento vertical da comunidade fitoplanctônica nos máximos subsuperficiais de clorofila (MSC) ao longo da termoclina devido a propagação de ondas internas na porção externa da Plataforma Continental Sudeste do Brasil. A região está sujeita as intrusões da Água Central do Atlântico Sul (ACAS) e a coluna de água permanece estratificada entre a primavera e o verão. Altas concentrações de nutrientes na camada de fundo dominada pela ACAS sustentam a produção nova da comunidade fitoplanctônica nos MSC da base da zona eufótica. Dados hidrográficos e biogeoquímicos tais como temperatura, salinidade, nutrientes, clorofila-a e taxas de fotossíntese foram monitorados durante uma série temporal diurna de 48 horas sobre a isóbata de 100 metros ao largo da Ilha de São Sebastião (SP) em intervalos de 1 hora. Entretanto, apesar da disponibilidade de nutrientes, a produção fotossintética pode ser limitada pela baixa intensidade luminosa nesses níveis. O movimento vertical induzido por ondas eleva o MSC, colocando-o em uma profundidade mais iluminada e podendo aumentar significativamente a produtividade local. Ao contrário do que observado na literatura, a passagem de ondas internas não aumentou a concentração de nutrientes na camada de mistura. Os resultados revelaram que as ondas internas podem aumentar em até $24 \%$ a fixação de carbono e, portanto, sugerem que as estimativas de produção primária obtidas até agora na zona eufótica do Embaiamento de Santos devem ser reavaliadas. 


\begin{abstract}
The aim of this research is to evaluate the effect of the vertical displacement of phytoplankton community in subsurface chlorophyll maxima (SCM) on the primary production due to passage of internal waves at outer portion of Brazilian southwestern continental shelf. The study area is influenced by intrusions of South Atlantic Central Water (SACW) thus allowing the water column to remain stably stratified during spring and summer seasons. The new primary production in the SCM at the base of the euphotic zone is sustained by high nutrient concentration in subthermocline portion of the water column, which is directly influenced by SACW intrusions. Hydrographic and biochemical data such as water temperature, salinity, nutrient and chlorophyll-a concentration, as well as photosynthesis rates, were monitored for roughly 48 hours at the fixed location over the $100 \mathrm{~m}$ isobath off Sao Sebastiao Island (Southeastern Brazil Bight). In spite of nutrient availability, photosynthetic production may be limited by low light conditions in subthermocline depths. Vertical displacements driven by internal wave propagation may increase light availability in the SCM, therefore having the potential to raise local productivity. Despite previous reports, no significant nutrient concentration increase in the mixed layer was observed during internal wave propagation. The results point to an increase in up to $30 \%$ of carbon fixation due to internal waves' passage and therefore suggest that previous estimates of primary productivity in the Santos Bight should be reviewed.
\end{abstract}




\section{Índice de figuras}

Figura 1: Exemplo de dois pacotes de ondas internas gerados por ciclos consecutivos de maré observados na Costa Sudeste Brasileira (Fonte: DIAS \& LORENZZETTI, 2013) 4

Figura 2: Representação esquemática da plataforma continental norte de São Paulo durante o verão. FHS significa frente halina superficial; FTP frente térmica profunda; PCI, PCM, PCE as regiões interna, média e externa da plataforma continental, respectivamente; NE é a direção nordeste; CB a Corrente do Brasil. As profundidades estão expressas em metros e as distâncias horizontais em km (Fonte: CASTRO, 1996)

Figura 3: Mapa da PCSE entre as latitudes $22^{\circ} \mathrm{S}$ e $25^{\circ} \mathrm{S}$ com as isóbatas de 40, 80, 120 e 200 metros. A estrela amarela indica a localização da estação fixa onde os dados foram coletados a $70 \mathrm{~km}$ da costa $\left(24.0^{\circ} \mathrm{S}, 44.5^{\circ} \mathrm{W}\right)$

Figura 4: Distribuição vertical e variação temporal da temperatura $\left({ }^{\circ} \mathrm{C}\right)$ na coluna de água sobre a isóbata de 100 metros ao largo de Ubatuba (SP) entre os dias 12 e 13 de abril de 2015. A isoterma de $19{ }^{\circ} \mathrm{C}$ esta realçada em vermelho.

Figura 5: Distribuição vertical e variação temporal da salinidade na coluna de água sobre a isóbata de 100 metros ao largo de Ubatuba (SP), entre 12 e 13 de abril de 2015. A isoterma de $19^{\circ} \mathrm{C}$ esta realçada em vermelho.

Figura 6: Distribuição vertical e variação temporal da concentração de oxigênio dissolvido sobre a isóbata de 100 metros ao largo de Ubatuba (SP), entre 12 e 13 de abril de 2015. A isoterma de $19^{\circ} \mathrm{C}$ esta realçada em vermelho. 13

Figura 7: Variação temporal da concentração de Nitrato $(\mu M)$ na Camada de Mistura, Máximo de Clorofila e Fundo sobre a isóbata de 100 metros ao largo de Ubatuba (SP), entre 12 e 13 de abril de 2015

Figura 8: Variação temporal da concentração de Nitrito $(\mu \mathrm{M})$ na Camada de Mistura, Máximo de Clorofila e Fundo sobre a isóbata de 100 metros ao largo de Ubatuba (SP), entre 12 e 13 de abril de 2015. 
Figura 9: Variação temporal da concentração de Silicato $(\mu \mathrm{M})$ na Camada de Mistura, Máximo de Clorofila e Fundo sobre a isóbata de 100 metros ao largo de Ubatuba (SP), entre 12 e 13 de abril de 2015. 15

Figura 10: Variação temporal da concentração de Fosfato $(\mu \mathrm{M})$ na Camada de Mistura, Máximo de Clorofila e Fundo sobre a isóbata de 100 metros ao largo de Ubatuba (SP), entre 12 e 13 de abril de 2015 16

Figura 11: Distribuição vertical e variação temporal da concentração de clorofila-a sobre a isóbata de 100 metros ao largo de Ubatuba (SP), entre 12 e 13 de abril de 2015. A isoterma de $19{ }^{\circ} \mathrm{C}$ esta realçada em vermelho.

Figura 12: Variação temporal da densidade celular do nanoplâncton, picoplâncton eucarioto e procarioto dominado por Synechococcus spp. na Camada de Mistura, Máximo de Clorofila e Fundo, sobre a isóbata de 100 metros ao largo de Ubatuba-SP entre 12 e 13 de abril de 2015

Figura 13: Curvas de Luz $\left(\mu E \cdot \mathrm{m}^{-2} \cdot \mathrm{s}^{-1}\right)$ versus Fotossíntese e parâmetros fotossintéticos (tabela vermelha) dos máximos de clorofila (DCM1, DCM2, DCM3 e DCM4) amostrados na isóbata de 100 metros ao largo de Ubatuba-SP entre 12 e 13 de abril de 2015. 20

Figura 14: Curvas de Luz $\left(\mu \mathrm{E} . \mathrm{m}^{-2} . \mathrm{s}^{-1}\right)$ versus transporte de elétrons e parâmetros fotossintéticos (tabela vermelha) dos máximos de clorofila (DCM5 e DCM6) amostrados na isóbata de 100 metros ao largo de Ubatuba-SP entre 12 e 13 de abril de 2015.......... 21

Figura 15: Séries temporais de altura do nível do mar e profundidade da isoterma de $19^{\circ} \mathrm{C}$ entre 12 e 13 de abril de 2015

Figura 16: Qualidade espectral da luz incidente na coluna de água nas profundidades relativas a 100\%, 75\%, 50\%, 25\% e 10\% da irradiância em superfície. Dados do projeto ANTARES, obtidos na isóbata de 40 metros ao largo de Ubatuba em maio de 2012.

Figura 17: Radiação Fotossinteticamente Ativa incidente em Ubatuba entre os dias 12 e 13 de abril de 2015.

Figura 18: Intensidade da irradiância entre 440 e 500nm, incidente na coluna de água na isóbata de 100 metros ao largo de Ubatuba entre 12 e 13 de abril de 2015....... 23 
Figura 19: Estimativa da produção primária modelada com base na luz incidente ao longo da coluna de água sobre a isóbata de 100 metros em Ubatuba, entre 12 e 13 de abril de 2015 24

Figura 20: (a) Irradiância solar ao longo da coluna de água e (b) Curva de Luz versus Fotossíntese ilustrando variações na profundidade e nas taxas fotossintéticas do máximo sub-superficial devido passagem de ondas internas. 28 


\section{Índice de tabelas}

Tabela 1: Valores de Clorofila-a integrados (mg.m $\left.{ }^{-2}\right)$ na Zona Eufótica e nos MSC observados entre 12 e 13 de abril de 2015 ao largo de Ubatuba...................................... 17

Tabela 2: Valores de Produção Primária integrados $\left(\mathrm{mgC} \cdot \mathrm{m}^{-2} \cdot \mathrm{d}^{-1}\right)$ na Zona Eufótica e nos MSC observados entre 12 e 13 de abril de 2015 ao largo de Ubatuba.................... 24 


\section{Introdução}

A produção de matéria orgânica e o fluxo de carbono no ambiente marinho dependem das taxas de fotossíntese do fitoplâncton, uma comunidade altamente diversificada de microalgas e bactérias que formam, portanto, a base da cadeia alimentar dos oceanos (MARGALEF, 1978). Através da fotossíntese, o fitoplâncton acumula compostos orgânicos (carboidratos, aminoácidos e proteínas) que são redistribuídos na teia alimentar pelágica (LONGHURST, 1991). Geralmente, o nitrogênio é o nutriente limitante da produtividade fitoplanctônica nos oceanos (CARPENTER \& CAPONE, 1983), podendo ser suprido a partir de várias fontes nas formas de nitrato, nitrito, amônia, aminoácidos e ureia. De acordo com Dugdale e Goering (1967) a produção primária oceânica pode ser classificada com base na fonte e no estado de oxidação dos compostos nitrogenados assimilados pelo fitoplâncton em: (i) produção regenerada, quando o nitrogênio é suprido pela regeneração microbiana dentro da camada eufótica e (ii) produção nova, quando o nitrogênio é oriundo de fontes externas e introduzido na zona eufótica por processos físicos.

As interações físicas e biológicas do ecossistema marinho ocorrem em diversas escalas temporais e espaciais, desde grandes bacias oceânicas (1000 km), ressurgências locais $(100 \mathrm{~km})$, até a menor escala de turbulência e difusão que afetam células individuais (cm) (MANN \& LAZIER, 2006). Especificamente as plataformas continentais (PC) são ecossistemas de transição com alto hidrodinamismo onde a produção nova (sensu DUGDALE \& GOERING, 1967) tende a dominar a produção total. Por essa razão, apesar de representarem menos de $10 \%$ da área total dos oceanos, são responsáveis por cerca de $20 \%$ da produção do oceano global e $47 \%$ da exportação de carbono para o oceano profundo (JAHNKE, 2010). Do ponto de vista sócio-econômico, a captura de pescado nas PC pode chegar a 90\% da pesca mundial, movimentando cerca de 211 bilhões de dólares por ano (PAULY et al., 2002; DYCK \& SUMAILA, 2010).

Devido à importância das plataformas continentais, a interação de processos físicos e biogeoquímicos vem sendo o foco de diversos estudos que buscam quantificar o fluxo de matéria orgânica entre a zona costeira e as bacias oceânicas adjacentes e a contribuição desses fluxos para o ciclo global do carbono (MANN \& LAZIER, 2006; SIMPSON \& SHARPLES, 2012). De modo geral, a fotossíntese em plataformas continentais fisicamente estratificadas, como ocorre na região Sudeste do Brasil (BRANDINI, 1990; 
CASTRO et al., 2006), é limitada pela disponibilidade de nutrientes nas camadas superiores e pela intensidade da luz na camada de fundo (BRANDINI, 1990; BRANDINI et al., 2013). Processos físicos como meandros, vórtices e a ação dos ventos nordeste causam ressurgências ou intrusões da Água Central Do Atlântico Sul (ACAS), fria e rica em nutrientes novos na base da camada eufótica (CASTRO et al., 2006). São processos de diversas magnitudes geográficas, desde a zona costeira até a quebra da plataforma continental (MESQUITA et al., 1993).

Ventos paralelos à costa geram correntes na superfície do oceano estabelecem um fluxo perpendicular à costa conhecido como Transporte de Ekman (SIMPSON \& SHARPLER, 2012) que afasta águas superficiais em direção ao oceano aberto e induzem movimentos da ACAS em direção à costa (CASTRO-FILHO et al., 1987). Se este processo tiver escala de tempo e espaço suficiente, o grau de estratificação na região pode aumentar criando um cenário hidrográfico perfeito para a propagação de ondas internas. Estas podem ser geradas devido ao estresse do vento e à ação da maré (GARRETT \& MUNK, 1979). Algumas das maiores ondas internas são observadas no Mar do Sul da China, com amplitudes de 140 metros ou mais (LIU et al., 2006). Nessa região, Pan et al. (2012) observaram um aumento significativo na biomassa e na produção fitoplanctônica em áreas de dissipação e propagação de ondas internas. Os movimentos verticais das picnoclinas podem aumentar a produção primária nova de comunidades encontradas em sub-superficie que se desenvolvem na nutriclina sob baixas intensidades de luz (HOLLOWAY, 1984; HOLLOWAY \& DENMAN, 1989; LANDE \& YENTSCH, 1988). Em plataformas continentais com estratificação, o efeito de ondas internas na produção primária está associado a mistura da coluna de água devido a dissipação da energia propagada nas picnoclinas, fertilizando camadas superficiais exauridas em nutrientes (CULLEN et al., 1983; SANDSTROM \& ELLIOT, 1984; SANGRÀ et al., 2001; ÁLVAREZ BORREGO et al., 2002).

A produção primária vem sendo estudada na plataforma do Estado de São Paulo por diversos autores que buscam compreender a estrutura e a dinâmica do ecossistema pelágico e sua relação com o regime hidrográfico (BRANDINI, 1988; METZLER et al., 1991; AIDAR et al., 1993; GAETA, 1999; GAETA et al., 1999; SALDANHACORREA, 1999). Como mencionado acima a intrusão da Água Central do Atlântico Sul (ACAS) é o principal processo de fertilização da camada eufótica com nutrientes novos na região, sobretudo durante o verão com a maior incidência de ventos do quadrante 
nordeste. Segundo Cerda e Castro (2014), intrusões da ACAS na PCSB durante o verão e a primavera, podem atingir a isóbata de 25-30 metros na região de Ubatuba. Brandini et al. (1989) identificaram altas concentrações de oxigênio dissolvido associados a Máximos Sub-superficiais de Clorofila-a (MSCs), sugerindo alta produtividade fitoplanctônica em regiões sujeitas à intrusão da ACAS. Curvas de luz-fotossíntese (CLF) obtidas em diferentes profundidades da zona eufótica comprovaram a fotoadaptação do fitoplâncton em níveis com baixas intensidades de luz nos meses de verão e primavera (BRANDINI, 1990; CHUQUI, 2013). Uma porcentagem considerável da produção primária da Plataforma Continental Sudeste Brasileira (PCSE) pode estar relacionada com o MSC, contribuindo na manutenção de recursos pelágicos e demersais. Grande parte dos peixes na plataforma de São Paulo desovam no verão (KATSURAGAWA et al., 1993), justamente quando ocorre a intrusão da ACAS e os MSCs se intensificam e se estendem espacialmente até zonas de plataforma interna (BRANDINI et al., 2013).

Estudos com base em séries temporais na PCSE observaram o movimento vertical das isotermas na coluna de água devido a propagação da maré interna (PEREIRA \& CASTRO, 2007). A maré barotrópica que propaga no oceano profundo transfere parte da energia para a termoclina/picnoclina ao atingir a quebra da plataforma continental, gerando a maré interna que se propaga em direção a costa, com amplitudes de dezenas de metros (APEL et al., 1985). Lorenzzetti e Dias (2013) identificaram em imagens de satélites (figura 1) diversos pacotes de ondas internas se propagando nas porções média e externa da PCSE principalmente no verão, sendo gerados pela componente $\mathrm{M}_{2}$ de maré, cujo o período é de aproximadamente 12 horas. Os autores sugerem a hipótese da constante quebra de ondas internas na região as quais, associadas à mistura causada pelo vento, mantém a plataforma interna bem misturada ao longo do ano. Também enfatizam que a propagação de ondas internas na plataforma continental pode ter um papel relevante na produção biológica. 


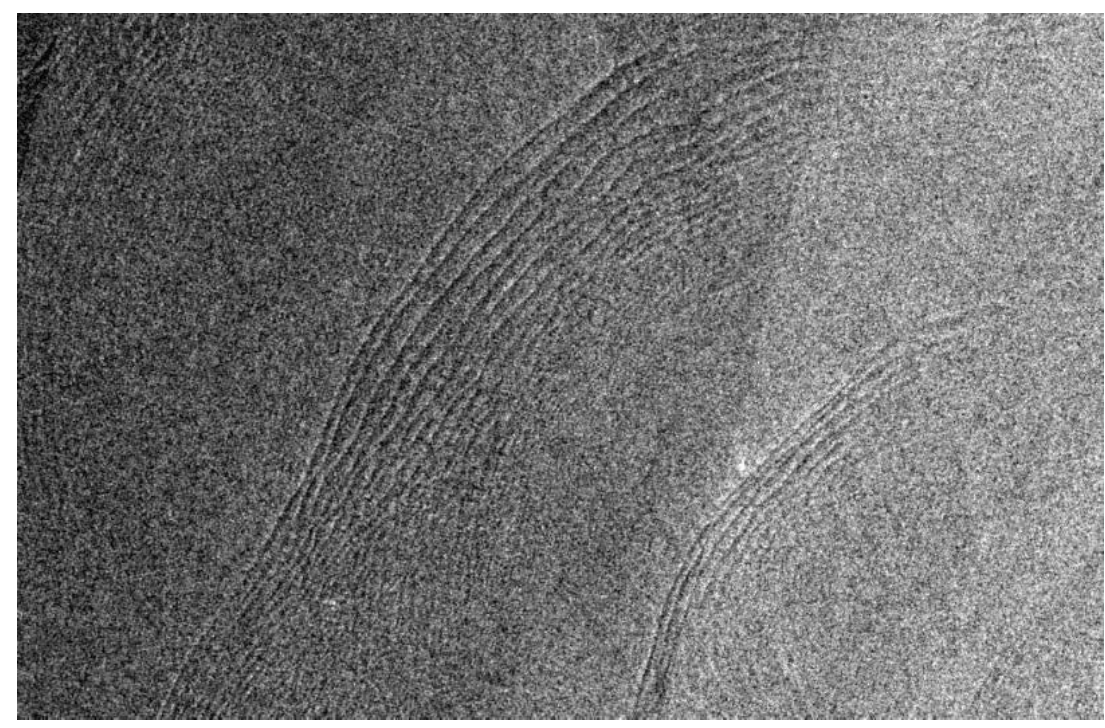

Figura 1: Exemplo de dois pacotes de ondas internas gerados por ciclos consecutivos de maré observados na Costa Sudeste Brasileira (Fonte: DIAS \& LORENZZETTI, 2013).

Gaeta e Brandini (2006) ressaltam a propagação de ondas internas como um mecanismo de fertilização que tem sido negligenciado. A amplitude das ondas internas é relativamente grande nos setores com profundidades entre 50 e 200 metros onde os limites da zona eufótica (1\% de luz solar da superfície) são comuns entre 60 e 70 metros (BRANDINI, 1990; BRANDINI et al., 2013). Portanto, o movimento vertical do MSC devido à passagem de ondas internas na PCSE pode elevar a atividade fotossintética do fitoplâncton devido ao aumento na radiação fotossinteticamente ativa (RFA), incrementando a produção primária e a assimilação de carbono inorgânico.

\section{Objetivos}

\subsection{Objetivo Geral}

O objetivo deste trabalho é avaliar a contribuição da fertilização da zona eufótica por ondas internas na produção primaria da Plataforma Continental Sudeste Brasileira.

\subsection{Objetivos Específicos}

i. Detectar variações nas concentrações de nutrientes na camada de mistura devido à propagação de ondas internas.

ii. Analisar a eficiência fotossintética e a biomassa fitoplanctônica ao longo da coluna de água no tempo.

iii. Estimar a variação na produtividade primária em função das oscilações na RFA como consequência da passagem de ondas internas. 


\section{Materiais e Métodos}

\section{1 Área de Estudo}

A PCSE se estende de Cabo Frio, no Rio de janeiro, até o Cabo de Santa Marta, Santa Catarina e sua largura varia de $230 \mathrm{~km}$ em frente a Santos a $50 \mathrm{~km}$ em frente a Cabo Frio (ZEMBRUSKI et al., 1979). Segundo Castro (1996), a PCSE pode ser dividida em três setores: Plataforma Continental Interna (PCI), Plataforma Continental Média (PCM) e Plataforma Continental Externa (PCE) (figura 2). A PCI é caracterizada pela presença da Água Costeira (AC) resultante da mistura da água da descarga continental com a água da plataforma continental, sendo seus limites a costa e a Frente Térmica Profunda (FTP, sensu CASTRO et al., 1987). A FTP representa o limite entre aguas costeiras não estratificadas, sujeitas a turbulência pela maré, das aguas de plataforma média estratificadas, devido a presença da ACAS no fundo com temperaturas entre 15 e $20^{\circ} \mathrm{C}$ e salinidade entre 35 e 36 (MIRANDA, 1982; CASTRO et al., 2006; SILVEIRA, 2007). A largura da PCI muda ao longo do ano, variando de 10-30 km no verão e 40-80 km no inverno (CASTRO, 1996).

A PCM está localizada entre a FTP e a Frente Halina Superficial (FHS), sendo esta última o limite entre a AC e a Água Tropical (AT). A característica principal da PCM é a forte estratificação da coluna de água devido a presença da ACAS nas maiores profundidades e da AC na superfície. Durante o inverno, seus limites se aproximam a ponto de colapsar para dimensões muito reduzidas. Contudo, durante a estação que está mais ativa, a PCM pode atingir 10-30 km de largura incluindo as isóbatas de 20 a 40 metros (figura 2).

Durante o verão, os ventos na região costeira têm predominância de leste-nordeste entre $15^{\circ} \mathrm{S}$ e $35^{\circ} \mathrm{S}$. Tomando como base o transporte de Ekman, ventos do primeiro quadrante, paralelos à costa, impulsionam as águas superficiais (AC) para o oceano, favorecendo a intrusão de águas mais profundas (ACAS) em regiões próximas à costa.

Durante o inverno, os ventos de leste-nordeste ficam confinados às latitudes de $20^{\circ} \mathrm{S}$ e $25^{\circ} \mathrm{S}$, e, abaixo de $25^{\circ} \mathrm{S}$, passam a predominar ventos oriundos de oeste-sudoeste. $\mathrm{O}$ enfraquecimento dos ventos provenientes do primeiro quadrante na região sudeste durante o inverno possibilita a entrada de frentes frias com maior frequência que resulta no Transporte de Ekman de águas superficiais em direção à costa. Este movimento, 
basicamente, é responsável pelo afastamento da ACAS, resultando na homogeneização da coluna de água e na presença exclusiva da AC (CASTRO et al., 2006).

O ponto de amostragem do presente estudo está localizado na porção norte da PCSB, na região de Ubatuba (isóbata de 100 metros). Segundo Cerda e Castro (2014), a coluna de água nesta região permanece estratificada ao longo do ano todo. No verão e na primavera a estratificação é geralmente mais intensa devido intrusões mais intensas da ACAS. Entretanto, a profundidade da termoclina e o estado nutricional da ACAS podem variar, devido respectivamente a intensidade e periodicidade dos ventos favoráveis à intrusão da ACAS, e ao tempo em que esta ocupa a zona eufótica (AIDAR et al., 1993).

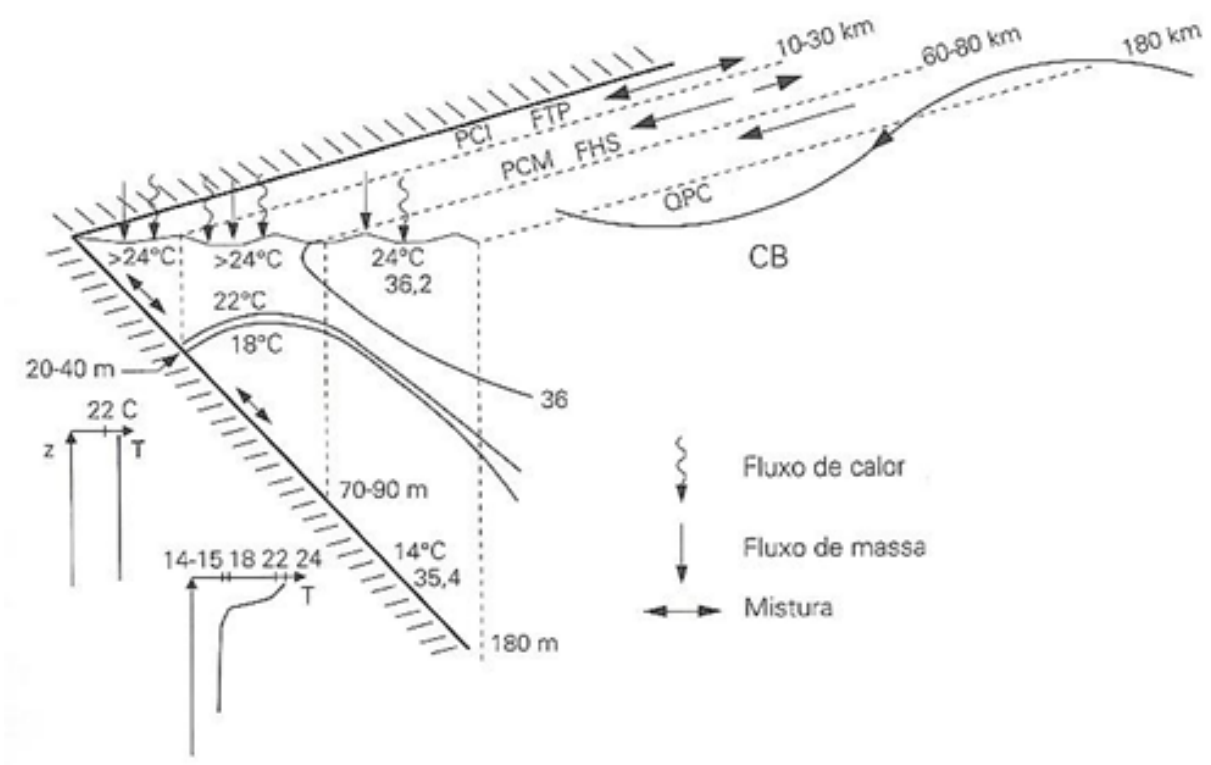

Figura 2: Representação esquemática da plataforma continental norte de São Paulo durante o verão. FHS significa frente halina superficial; FTP frente térmica profunda; PCI, PCM, PCE as regiões interna, média e externa da plataforma continental, respectivamente; NE é a direção nordeste; CB a Corrente do Brasil. As profundidades estão expressas em metros e as distâncias horizontais em km (Fonte: CASTRO, 1996).

\subsection{Aquisição de dados}

\subsubsection{Dados in situ}

Foi realizada uma série temporal nas proximidades da isóbata de 100 metros de profundidade da PCSE (figura 3), a bordo do N. Oc. Alpha Delphini da Universidade de São Paulo nos dias 12 e 13 de abril de 2015. 


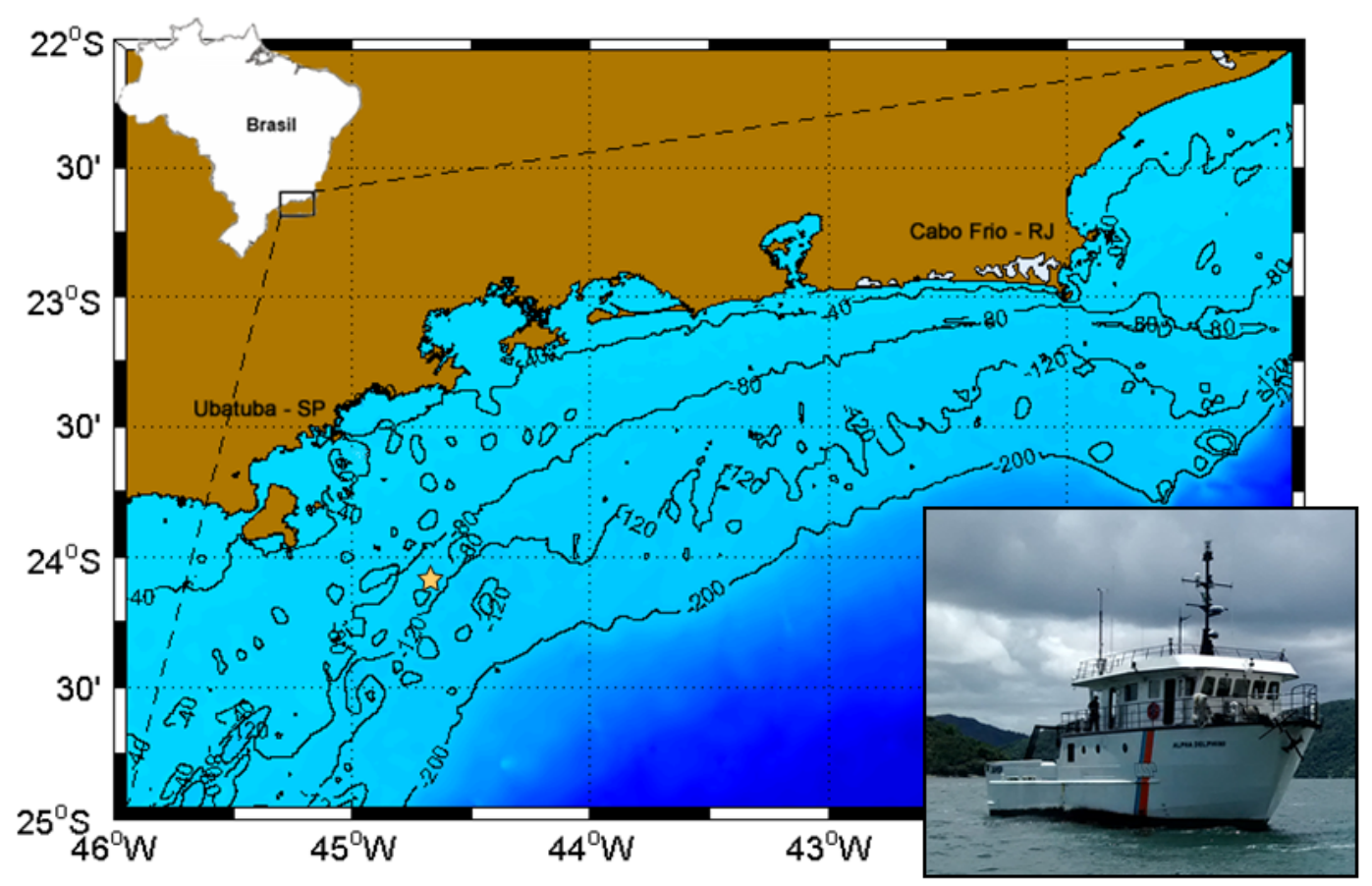

Figura 3: Mapa da PCSE entre as latitudes $22^{\circ} \mathrm{S}$ e $25^{\circ} \mathrm{S}$ com as isóbatas de 40, 80, 120 e 200 metros. A estrela amarela indica a localização da estação fixa onde os dados foram coletados a $70 \mathrm{~km}$ da costa $\left(24.0^{\circ} \mathrm{S}, 44.5^{\circ} \mathrm{W}\right)$.

Durante o período diurno do cruzeiro, foram adquiridos perfis de temperatura, salinidade, oxigênio dissolvido e fluorescência (clorofila-a) utilizando uma sonda multiparamétrica EXO2 da YSI, com intervalo de aproximadamente 1 hora. O equipamento foi calibrado na semana anterior ao embarque, utilizando protocolos e soluções específicas segundo o manual do fabricante.

Amostras de água foram coletadas em profundidades referentes a camada de mistura (15 metros), máximo de clorofila (máximo de fluorescência) e camada inferior (90 metros) com garrafas de 2,5 litros acopladas a um sistema de Roseta-CTD Seabird 19plus. As profundidades de coleta foram estabelecidas de acordo com o perfil de temperatura e fluorescência obtido previamente com a EXO2. Amostras discretas foram coletas na manhã, meio do dia e final da tarde de dois dias consecutivos totalizando 6 coletas no ponto fixo. Em cada coleta, foram coletadas amostras de água para análises de nutrientes dissolvidos, clorofila-a, citometria de fluxo e produtividade primária. Após a coleta, as amostras foram mantidas em galões térmicos escuros e filtradas o mais rápido possível no laboratório da embarcação. A concentração de clorofila-a estimada pela fluorescência in situ foi corrigida pelos valores obtidos com as análises discretas de clorofila através de interpolação linear. 


\subsubsection{Nutrientes dissolvidos e Clorofila a}

Amostras de água do mar foram filtradas a bordo em filtros GF/F de 0,7 $\mu \mathrm{m}$ de porosidade para determinar a concentração de nutrientes dissolvidos e clorofila a. Os filtros para análise de clorofila a foram armazenados em nitrogênio líquido com o intuito de preservar o conteúdo pigmentar. Alíquotas de água do mar filtrada foram armazenadas em frasco de polipropileno e mantidas congeladas $\left(-20^{\circ} \mathrm{C}\right)$ para futuras analises de nitrato, nitrito, fosfato e silicato. Os nutrientes dissolvidos foram analisados por colorimetria (GRASSHOFF, 1976) em um analisador automático AA2 (Seal Analytical) no Laboratório de Biogeoquímica de Nutrientes, Micronutrientes e Traços nos Oceanos (LABNUT) do Instituto Oceanográfico da Universidade de São Paulo (IOUSP). A clorofila-a ativa do fitoplâncton retido nos filtros, foi extraída com Acetona (90\%) + DMSO durante 24 horas a $-20^{\circ} \mathrm{C}$. As concentrações no solvente foram determinadas pelo método fluorimétrico (WELSCHEMYER, 1994) no Laboratório de Produção Primária do IOUSP com um fluorímetro AU10 da Turner Design.

\subsubsection{Citometria de Fluxo}

A técnica de citometria de fluxo foi aplicada para analisar a composição da comunidade fitoplanctônica. Cada amostra (alíquotas de 1,5ml em duplicata) foi fixada com glutaraldeído (0,02\%) e armazenadas em nitrogênio líquido. As análises foram realizadas nas dependências do Laboratório de Microscopia do IOUSP seguindo o protocolo estabelecido por Marie et al.. (2004) em um Citômetro de Fluxo Accuri C6. O pós-processamento das amostras foi realizado com o software Flowing V2.5, com os “gates” propostos por Marie et al.. (2004) para determinar as densidades de células do Synechococcus spp., pico- e nanoplâncton.

\subsubsection{Produtividade Primária}

\subsubsection{Medidas de taxas de transporte de elétrons}

Medidas de taxas de transporte de elétrons foram realizas utilizando um FRRf MK2 (Chelsea Technology) em conjunto com um sistema de luz artificial (PSI SL3500 - 455 nm) instalado no laboratório da embarcação. Curvas de Luz versus Transporte de Elétrons Relativo (CLTER) foram construídas em um gradiente de luz azul controlado eletronicamente (17 intensidades entre 0 e $152 \mu \mathrm{E} \cdot \mathrm{m}^{-2} \cdot \mathrm{s}^{-1}$ por 2 minutos cada) em todas as amostras do MSC. Cada amostra foi ambientada no escuro por 30 minutos e antes de 
executar a rotina ajustou-se o "gain” do PMT e a intensidade do LED para obter valores de $F_{m}$ próximos de 24.000, como recomendado no manual do equipamento.

\subsubsection{Medidas das taxas de fotossíntese com a técnica de ${ }^{14} \mathrm{C}$}

Devido a restrições logísticas e de segurança no laboratório da embarcação, taxas de assimilação de carbono foram quantificadas apenas na última amostra de MSC coletada no cruzeiro. No sistema de luz artificial, retirou-se o FRRf do local para instalar uma incubadora de acrílico acoplada a um banho térmico de fluxo contínuo que manteve a temperatura das amostras constantes e igual à da profundidade de coleta. Três alíquotas de $50 \mathrm{~mL}$ de água do MSC foram incubadas por 2 horas com 1,5 mL de uma solução de $\mathrm{NaH}^{14} \mathrm{CO}_{3}(5 \mu \mathrm{Ci}$ por mL de solução de $\mathrm{pH}$ 9.0) nas intensidades de luz referente aos 3 últimos pontos das Curvas de Luz versus Transporte de Elétrons. Uma quarta alíquota foi incubada no compartimento escuro do banho térmico, com o intuito de quantificar a assimilação de carbono independente da luz. As amostras foram filtradas após o período de incubação e armazenadas em nitrogênio líquido para analises posteriores. A atividade radioativa (decaimentos por minuto - DPM) dos filtros $\left({ }^{14} \mathrm{C}\right)$ foi determinada através da técnica de cintilação líquida (adaptada de STEEMANN-NIELSEN, 1952) empregandose um espectrômetro de cintilação liquida da PerkinElmer Tri-Carb 2810, nas dependências do Laboratório de Radioisótopos do IOUSP. A partir dos valores de DPM calculou-se as taxas de assimilação de carbono com a equação descrita por Teixeira (1973a), normalizadas pela concentração de clorofila quantificada na amostra, expressas em mg C.mg $\mathrm{Clo}^{-1} \cdot \mathrm{h}^{-1}$. As CLTER foram convertidas em taxas de fotossíntese por concentração de clorofila_a (mg C. mg $\mathrm{Clo}^{-1} . \mathrm{h}^{-1}$ ) a partir de um fator obtido na amostra em que ambas as taxas foram medidas.

\subsubsection{Dados complementares}

\subsubsection{Irradiância e nível do mar}

Devido à falta de dados de irradiância ao longo do cruzeiro tanto em superfície, quanto na coluna de água, optou-se por utilizar os dados de irradiância medidos na Estação Meteorológica da Base de Ubatuba do IOUSP, que apesar da distância de 120 Km do ponto de coleta, são representativos em dias de céu aberto devido a pequena diferença de latitude entre os locais (KIRK, 1983). Os dados de irradiância solar total (todo espectro de luz) foram convertidos para radiação fotossinteticamente ativa (RFA, espectro entre 400 e 700nm) multiplicando por um fator de 0,45 (KIRK, 1983) e por 4,57 
para transformar a unidade de W.m $\mathrm{m}^{-2}$ para $\mu \mathrm{E} \cdot \mathrm{m}^{-2} \cdot \mathrm{s}^{-1}$ (THIMIJAN \& HEINS, 1983). Além de dados de irradiância, foram utilizados dados de altura do nível do mar coletados nessa estação meteorológica.

\subsubsection{Coeficiente de extinção de luz (k)}

O coeficiente de extinção da luz na água foi calculado a partir de dados de reflectância coletados remotamente pelo sensor MODIS a bordo do satélite AQUA e disponibilizados no site da NASA Ocean Color (www.oceancolor.gsfc.nasa.gov), analisadas no software Seadas V7.3.2. A partir da irradiância em superfície e do $k$, estimou-se a irradiância incidente em cada profundidade da coluna de água de hora em hora seguindo a Lei de Lambert-Bouguer (equação 1).

$$
I(z, t)=I_{o}(t) \cdot e^{(-k . z)}
$$

onde $t$ é o tempo em horas, $z$ é a profundidade em metros e $I_{0}$ a Irradiância solar em superfície.

\subsubsection{Qualidade Espectral}

A assimilação de carbono e o transporte de elétrons foram determinados com uma fonte de luz artificial azul (455nm) para evitar a influência de fótons vermelhos (>685 nm) no detector do FRRf, o que interfere nas medidas de fluorescência das amostras devido à semelhança espectral. Entretanto, a RFA incidente contém todo o espectro de luz visível entre 400 e 700nm). Para calcular a produção primária com as CLF construídas com luz azul, optou-se por trabalhar apenas com essa faixa do espectro de luz. O Projeto ANTARES vem monitorando as condições oceanográficas em uma estação fixa ao largo de Ubatuba ao longo de 10 anos, medindo variáveis físicas, químicas e bio-óticas ao longo da coluna de água, incluindo qualidade espectral da irradiância incidente coletados com um sensor hiper-espectral (HyperOCR Hyperspectral Radiometer - Satlantic). O ponto de amostragem desse Projeto se localiza na Plataforma Média na isóbata de $40 \mathrm{~m}$, onde as condições ambientais se assemelham as condições na isóbata de 100 metros (baixas concentrações de clorofila, coluna de água estratificada com luz azul predominando a partir dos 20 metros de profundidade) em algumas épocas do ano. A contribuição relativa (em porcentagem) da luz azul verificada com os dados do Projeto Antares foi aplicada nos valores de RFA adquiridos na Estação Meteorológica de Ubatuba. A partir disso, 
calculou-se a intensidade de luz azul em cada profundidade da coluna de água considerando constante o coeficiente de extinção da luz na água (k).

\subsubsection{Modelo de Produção Fitoplanctônica}

A produção primária foi calculada no período amostrado com um intervalo de 1 hora. Os parâmetros $P^{B}{ }_{M A X}$ e $\alpha$ das curvas de luz foram obtidos com um ajuste matemático realizado no software KaleidaGraph V4.0 segundo o modelo de Jassby e Platt (1976). Posteriormente, os parâmetros obtidos foram utilizados em conjunto com os dos dados de luz e clorofila para calcular a produção primária ao longo do tempo na coluna de água (equação 2).

$$
P(z, t)=[C l o](z, t) * P_{\max }^{B} * \tanh \left(\alpha * I(z, t) / P_{\max }^{B}\right)
$$

Onde [Clo](z,t) é a concentração de clorofila-a em função da profundidade e do tempo, $\mathrm{P}^{\mathrm{B}}$ MAX é a taxa máxima de assimilação de Carbono normalizada pela concentração de clorofila-a, $\alpha$ é a inclinação inicial da curva de saturação a baixas irradiâncias e $I(z, t)$ a irradiância incidente em função da profundidade e do tempo calculada pela equação 1.

\section{Resultados}

\subsection{Temperatura}

Em todos os perfis obtidos observou-se uma estratificação térmica na coluna de água e oscilações nas isotermas (figura 4). A temperatura na camada de mistura (0-20m) variou entre 24 e $25{ }^{\circ} \mathrm{C}$. A temperatura mínima de $15.3^{\circ} \mathrm{C}$ foi registrada na camada de fundo abaixo da termoclina na madrugada do primeiro dia no fundo. No segundo dia, a profundidade da isoterma de $17^{\circ} \mathrm{C}$ aumentou de 60 para 80 metros, enquanto a isoterma de $18^{\circ} \mathrm{C}$ permaneceu entre 50 e 60 metros. A profundidade da isoterma de $19^{\circ} \mathrm{C}$ (em vermelho) variou entre 41 e 55 metros. 


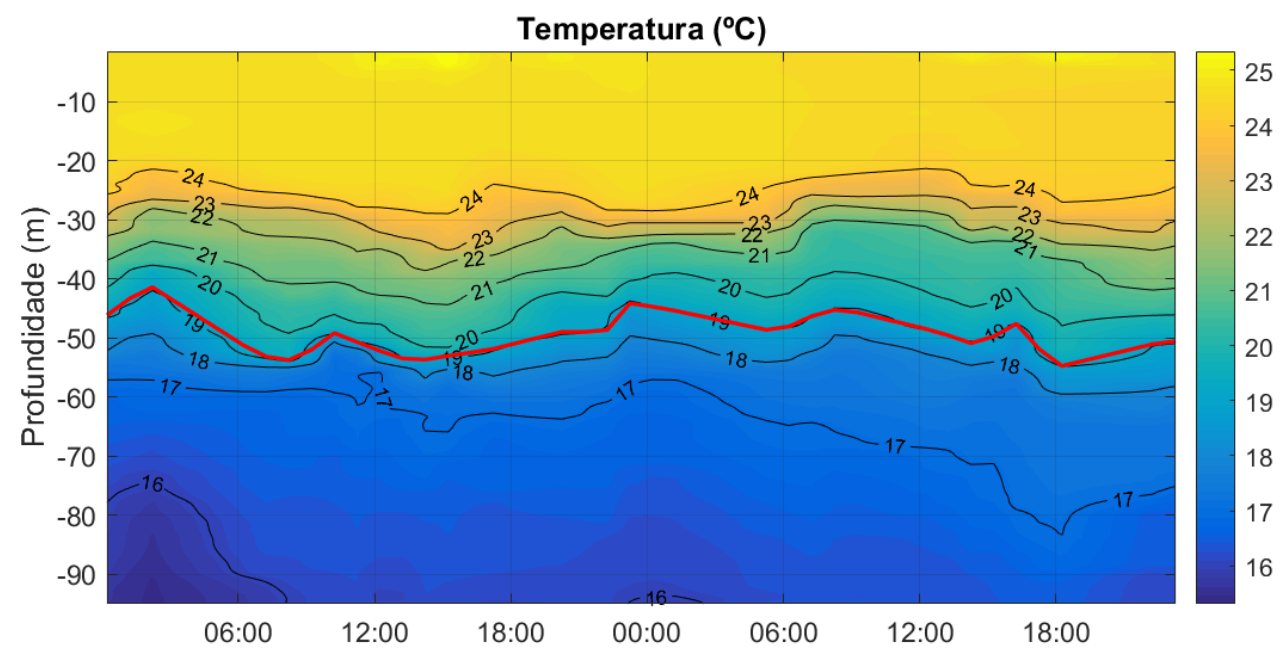

Figura 4: Distribuição vertical e variação temporal da temperatura $\left({ }^{\circ} \mathrm{C}\right)$ na coluna de água sobre a isóbata de 100 metros ao largo de Ubatuba (SP) entre os dias 12 e 13 de abril de 2015. A isoterma de $19{ }^{\circ} \mathrm{C}$ esta realçada em vermelho.

\subsection{Salinidade}

A salinidade variou entre 29 e 36 na coluna de água (figura 5). Os menores valores foram observados na superfície na noite entre os dois dias. A partir dos 20 metros a salinidade variou pouco entre 35 e 36 até o fundo, indicando a presença da ACAS. O padrão de distribuição vertical e de variação temporal da salinidade não acompanhou a da temperatura não sendo observada semelhança no comportamento das isolinhas desses parâmetros ao longo do tempo. Ao contrário, revelou anomalias na distribuição vertical sobretudo no período noturno entre as 18:00 horas do primeiro dia e as 06:00 horas do segundo dia de amostragem, quando colunas de menor salinidade invadiram a coluna de água acompanhadas de quedas bruscas de salinidade na superfície. 


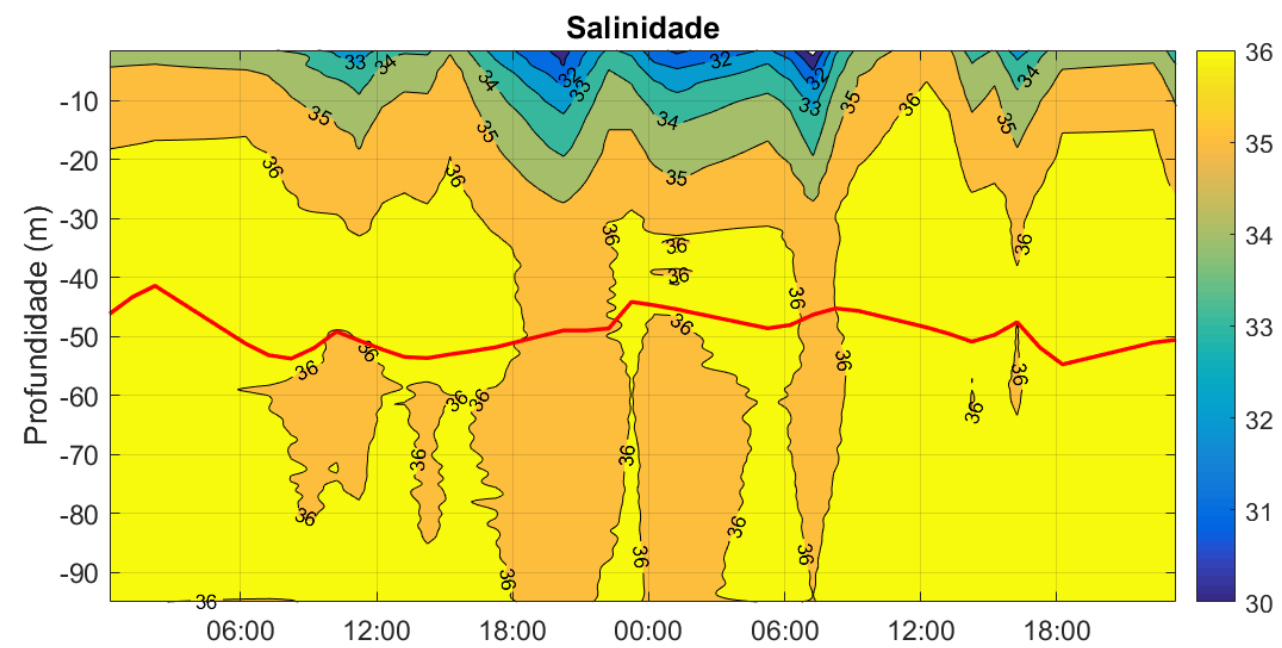

Figura 5: Distribuição vertical e variação temporal da salinidade na coluna de água sobre a isóbata de 100 metros ao largo de Ubatuba (SP), entre 12 e 13 de abril de 2015. A isoterma de $19{ }^{\circ} \mathrm{C}$ esta realçada em vermelho.

\subsection{Oxigênio dissolvido}

A concentração de oxigênio dissolvido variou entre 5,7 e 7,1 mg. $\mathrm{L}^{-1}$. Os menores valores foram observados na camada abaixo da termoclina associados à baixas temperaturas. Nos primeiros 40 metros de profundidade, a concentração de oxigênio dissolvido foi a cima de $6.6 \mathrm{mg} . \mathrm{L}^{-1}$ em todo período amostrado. Os valores máximos foram observados em superfície na madrugada do segundo dia, e em meia água no final do fotoperíodo dos dois dias (figura 6).

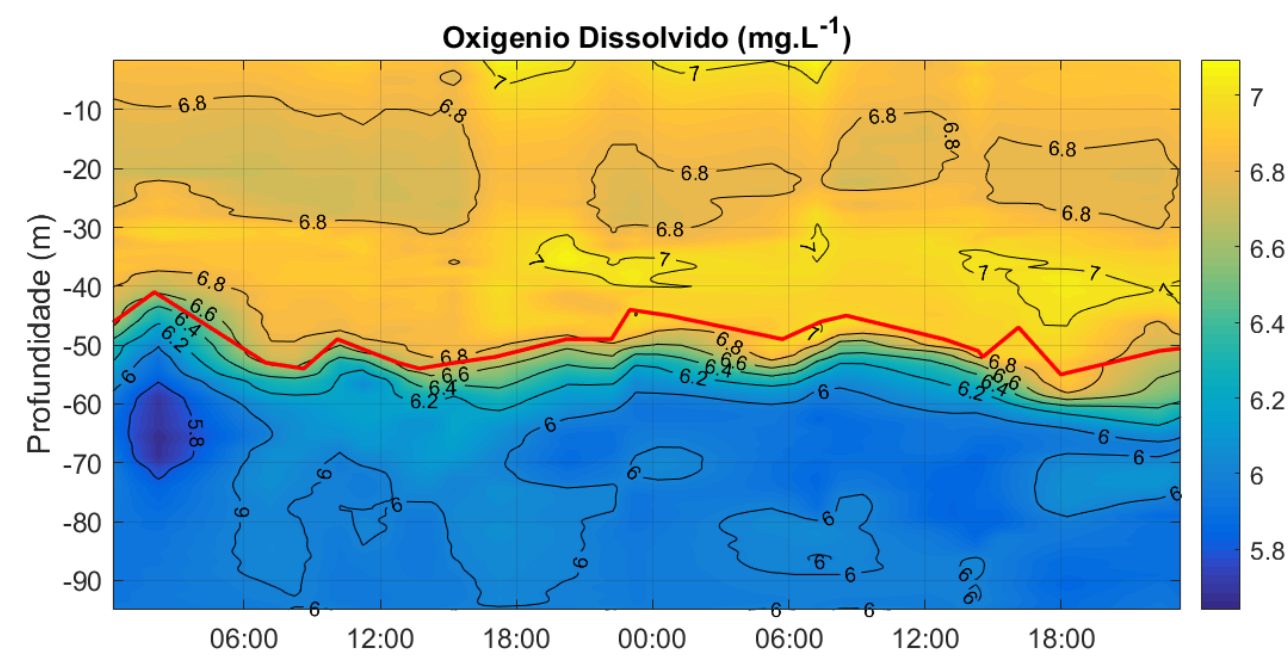

Figura 6: Distribuição vertical e variação temporal da concentração de oxigênio dissolvido sobre a isóbata de 100 metros ao largo de Ubatuba (SP), entre 12 e 13 de abril de 2015. A isoterma de $19{ }^{\circ} \mathrm{C}$ esta realçada em vermelho. 


\subsection{Nutrientes dissolvidos}

As maiores concentrações de nitrato foram observadas no fundo, acima de $4 \mu \mathrm{M}$ no período amostrado. $\mathrm{Na}$ camada de mistura as concentrações não variaram significativamente, permanecendo abaixo de 0,2 $\mu \mathrm{M}$ todo o tempo. No MSC, as concentrações de nitrato variaram entre 0,2 e 4,0 $\mu \mathrm{M}$, valores observados no fundo e na camada de mistura (figura 7).

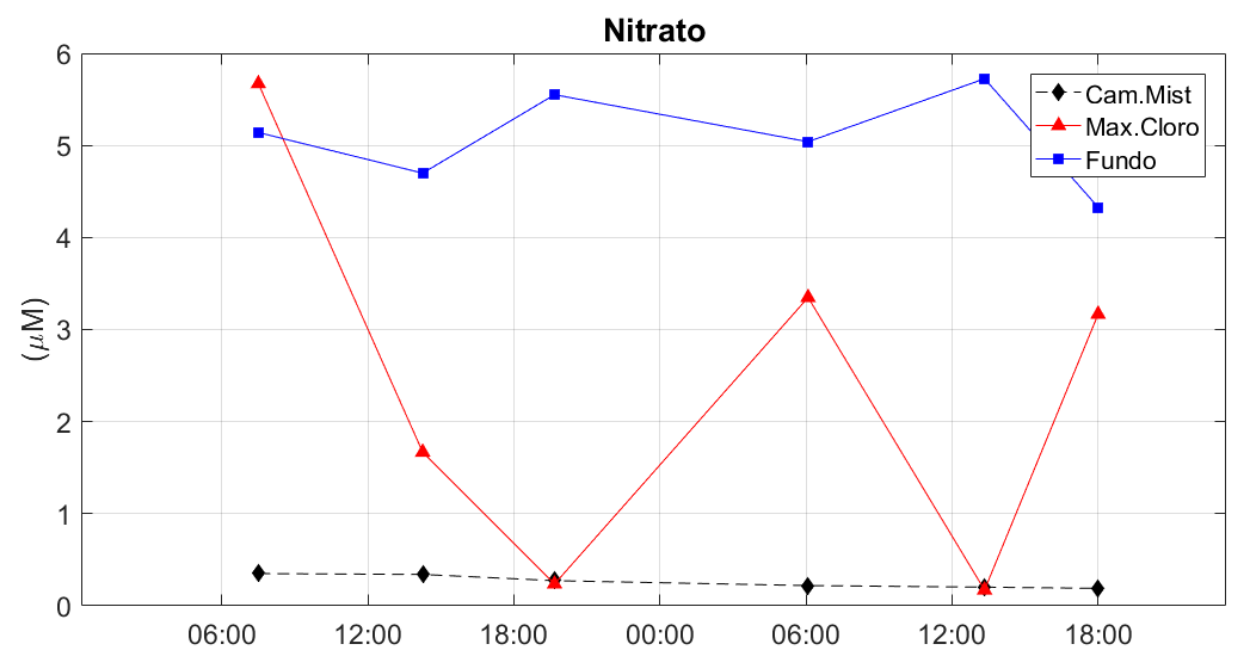

Figura 7: Variação temporal da concentração de Nitrato $(\mu \mathrm{M})$ na Camada de Mistura, Máximo de Clorofila e Fundo sobre a isóbata de 100 metros ao largo de Ubatuba (SP), entre 12 e 13 de abril de 2015.

As concentrações de nitrito variaram entre 0,04 e 0,18 $\mu \mathrm{M}$ (figura 8). Na camada de mistura os valores permaneceram abaixo de $0,11 \mu \mathrm{M}$ diminuindo para 0,04 $\mu \mathrm{M}$ ao longo do tempo. No fundo, a concentração de nitrito inicial foi de $0,11 \mu \mathrm{M}$ e permaneceu praticamente constante em $0,07 \mu \mathrm{M}$ a partir da metade do primeiro dia. Concentrações de nitrito maiores que $0,15 \mu \mathrm{M}$ foram encontradas no MSC. No fim de tarde do primeiro dia e as 13 horas do segundo dia, as concentrações de nitrito no MSC caíram para valores abaixo de $0,07 \mu \mathrm{M}$, menores que os encontrados no fundo. 


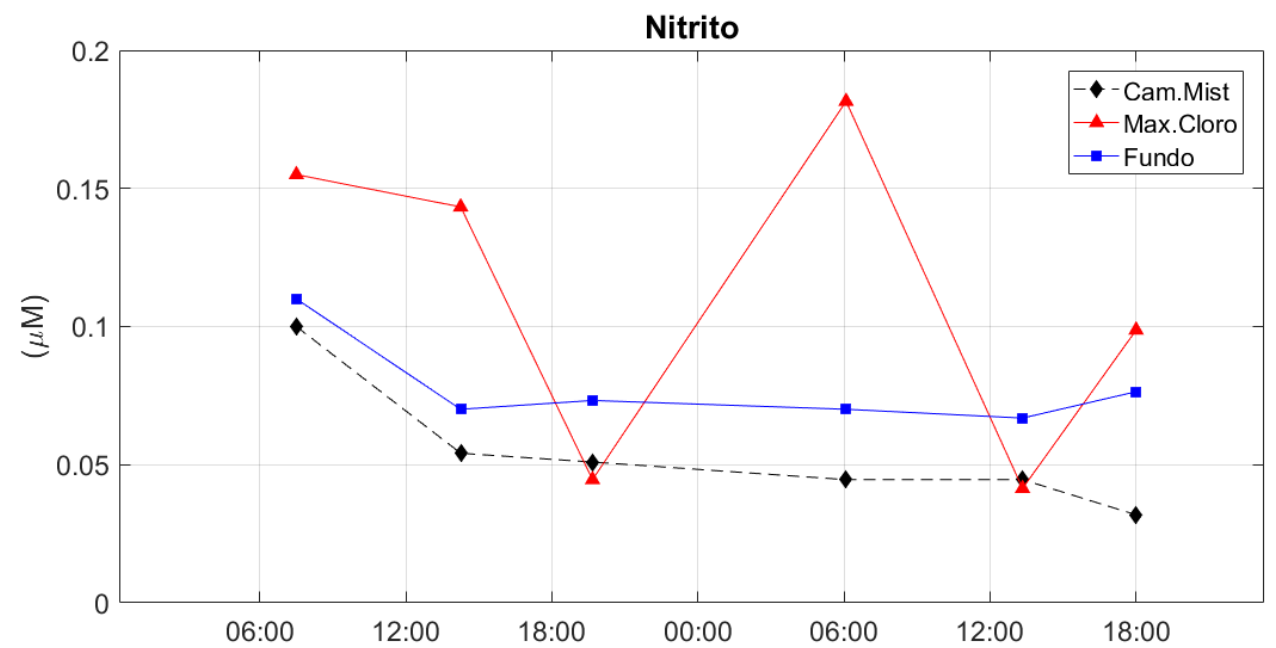

Figura 8: Variação temporal da concentração de Nitrito $(\mu M)$ na Camada de Mistura, Máximo de Clorofila e Fundo sobre a isóbata de 100 metros ao largo de Ubatuba (SP), entre 12 e 13 de abril de 2015.

$\mathrm{Na}$ camada de fundo foram encontradas as maiores concentrações de silicato, variando entre 2,5 e 4,1 $\mu \mathrm{M}$ ao longo do tempo. Na camada de mistura, a concentração máxima deste nutriente foi de 1,6 $\mu \mathrm{M}$ no início do primeiro dia, permanecendo em cerca de $1 \mu \mathrm{M}$ a partir da metade do primeiro dia. No MSC a concentração de silicato variou entre 1,2 e 3,4 $\mu \mathrm{M}$, com os valores mínimos observados às 19 horas do primeiro dia e às 13 horas do segundo dia (figura 9).

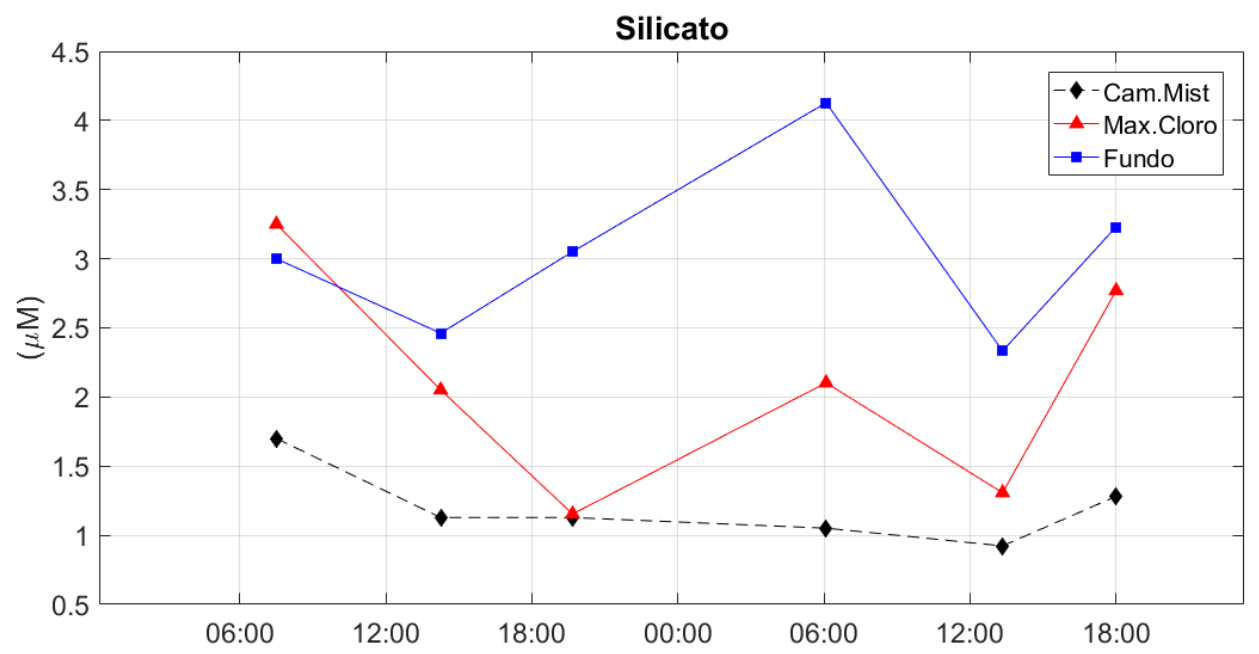

Figura 9: Variação temporal da concentração de Silicato $(\mu M)$ na Camada de Mistura, Máximo de Clorofila e Fundo sobre a isóbata de 100 metros ao largo de Ubatuba (SP), entre 12 e 13 de abril de 2015.

As menores concentrações de fosfato abaixo de $0,2 \mu \mathrm{M}$ foram observadas na camada de mistura em todo o período observado. Na camada de fundo a concentração de fosfato foi maior com valores próximos a $0,7 \mu \mathrm{M}$ na manhã do primeiro dia e a cima de 
0,5 $\mu \mathrm{M}$ a partir da metade do primeiro dia. No nível do MSC a concentração variou entre 0,18 e 0,55 $\mu \mathrm{M}$ no primeiro dia e permaneceu próxima a $0,4 \mu \mathrm{M}$ durante o segundo dia (figura 10).

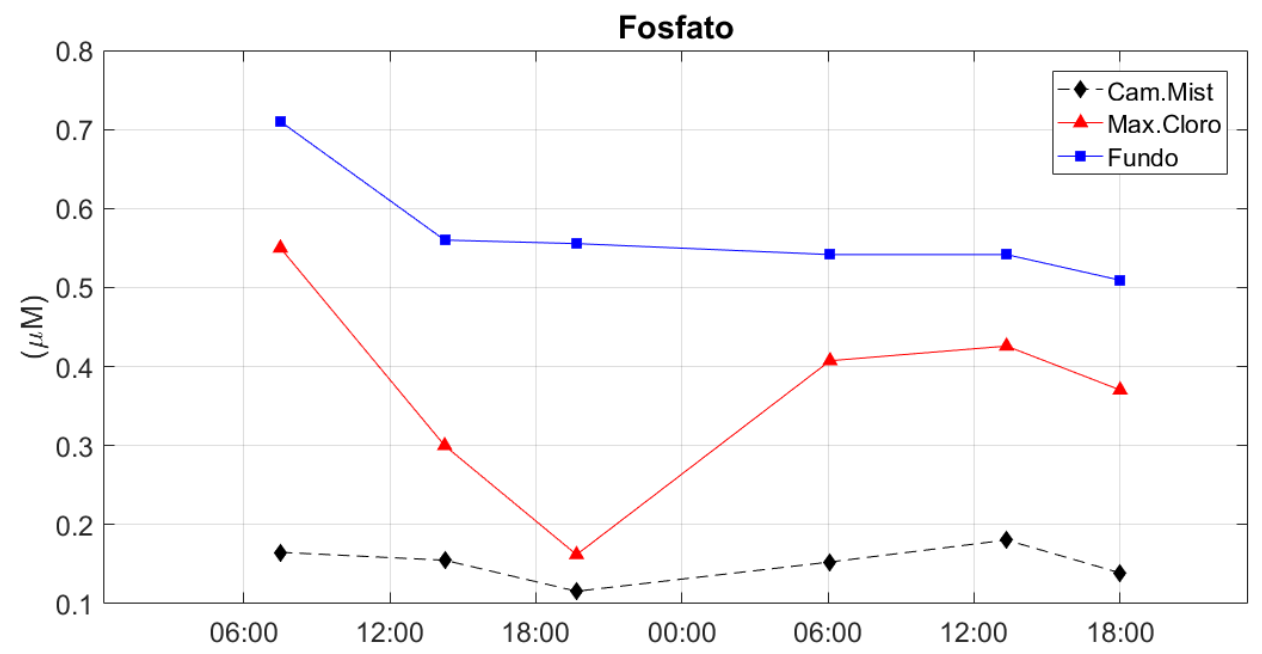

Figura 10: Variação temporal da concentração de Fosfato $(\mu \mathrm{M})$ na Camada de Mistura, Máximo de Clorofila e Fundo sobre a isóbata de 100 metros ao largo de Ubatuba (SP), entre 12 e 13 de abril de 2015.

\subsection{Clorofila-a e Citometria de Fluxo}

A concentração de clorofila-a variou entre 0,1 e 1,0 mg.m ${ }^{-3}$ com valores mínimos em torno 0,1-0,2 mg.m ${ }^{-3}$ e máximos em níveis sub-superficiais entre 40 e 60 metros de profundidade, associados à isoterma de $19^{\circ} \mathrm{C}$ (figura 11). Picos secundário de 0,9 mg.m ${ }^{-3}$ foram observados as 18:00hs em ambos os dias consecutivos. Na camada de mistura e abaixo da termoclina as concentrações de clorofila-a foram menores do que $0,15 \mathrm{mg} \cdot \mathrm{m}^{-3}$. A partir do segundo dia, observou-se um aumento da concentração abaixo de 70 metros de profundidade, o que certamente alterou a concentração integrada na coluna de água. 


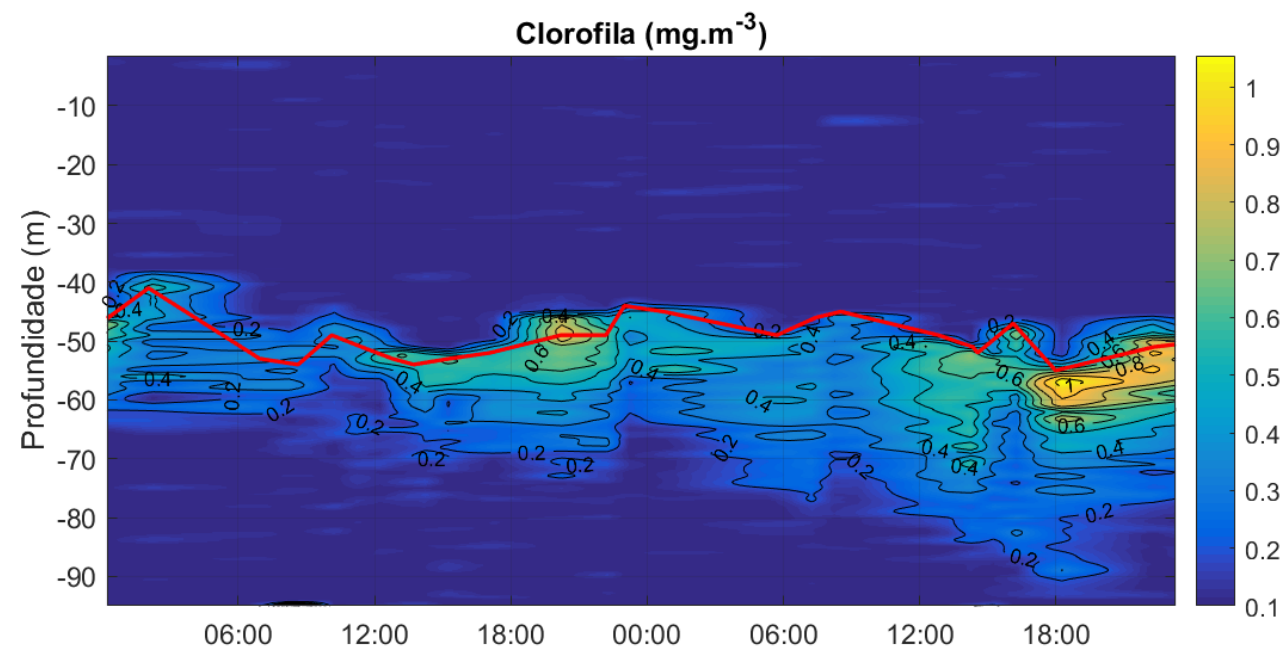

Figura 11: Distribuição vertical e variação temporal da concentração de clorofila-a sobre a isóbata de 100 metros ao largo de Ubatuba (SP), entre 12 e 13 de abril de 2015 . A isoterma de $19^{\circ} \mathrm{C}$ esta realçada em vermelho.

De fato, a clorofila-a integrada na zona eufótica foi de 14,9 e $18,7 \mathrm{mg} \cdot \mathrm{m}^{-2}$ no primeiro e no segundo dia, respectivamente com o MSC contribuindo com $41 \%$ e $37 \%$ na biomassa total encontrada no ambiente (tabela 1). Os valores máximos na coluna de água observados no segundo dia foram maiores e mais persistentes do que os observados no primeiro dia, o que explica o estoque maior integrado na zona eufótica.

Tabela 1: Valores de Clorofila-a integrados $\left(\mathrm{mg}^{\left.-\mathrm{m}^{-2}\right)}\right.$ na Zona Eufótica e nos MSC observados entre 12 e 13 de abril de 2015 ao largo de Ubatuba.

\begin{tabular}{|c|c|c|}
\hline Clorofila $_{\text {Integrada }}$ & Dia 1 & Dia 2 \\
\hline $0 m-Z_{\text {Eufótica }}$ & 14.9 & 18.7 \\
\hline $\mathrm{MSC}_{(40 \mathrm{~m}-60 \mathrm{~m})}$ & 6.1 & 7.0 \\
\hline MSC/PP.Z $Z_{\text {Eufótica }}$ & $41 \%$ & $37 \%$ \\
\hline
\end{tabular}

Nas amostras discretas a concentração de clorofila-a extraída in vitro variou entre 0,1 e 0,8 mg.m $\mathrm{m}^{-3}$ (figura 12). Na camada de mistura as concentrações foram baixas $(<0,1$ mg.m ${ }^{-3}$ ) e nos máximos sub-superficiais entre 40 e 60 metros variou entre 0,2 e 0,8 mg.m ${ }^{3}$. Na camada de fundo as concentrações foram baixas e com menor amplitude de variação entre 0,1 e $0,3 \mathrm{mg} \cdot \mathrm{m}^{-3}$.

A densidade celular do fitoplâncton dominante estimada por citometria de fluxo foi maior no MSC em relação a camada de mistura e a camada abaixo da termoclina. Synechococcus spp., principal representante do picoplancton procarioto, foi o mais abundante, contribuindo com mais de $80 \%$ do número total de células em todas as amostras. 

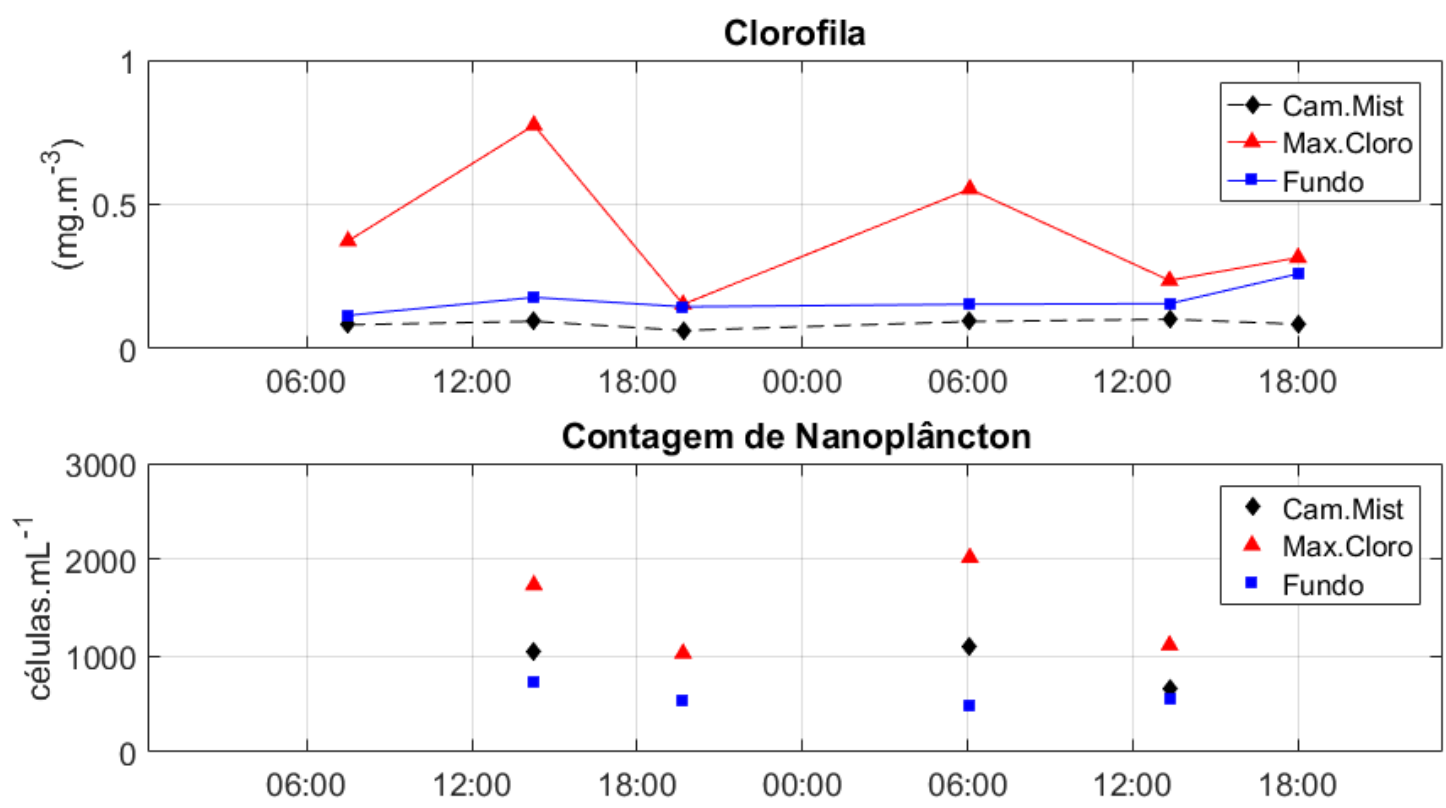

Contagem de Synechococcus spp.

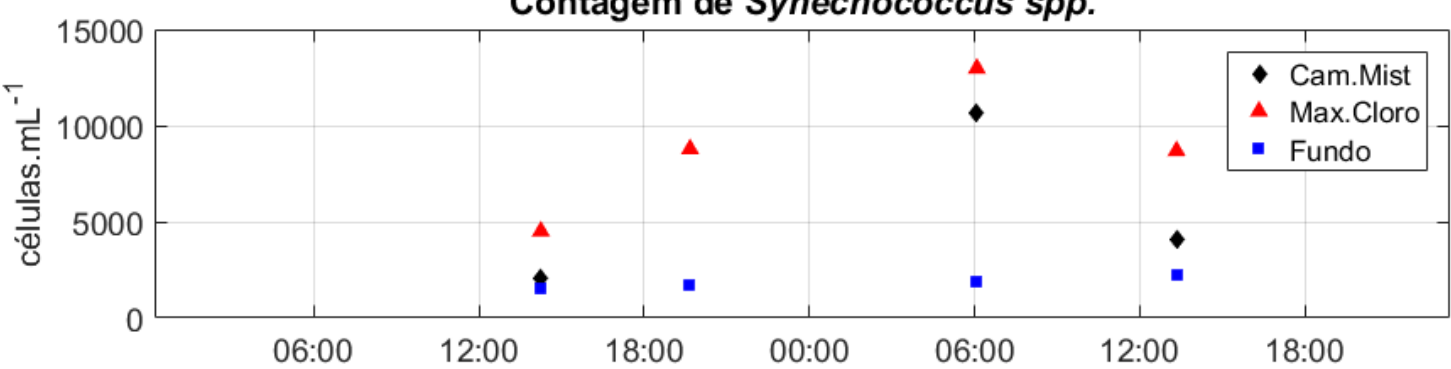

Contagem de Picoplâncton

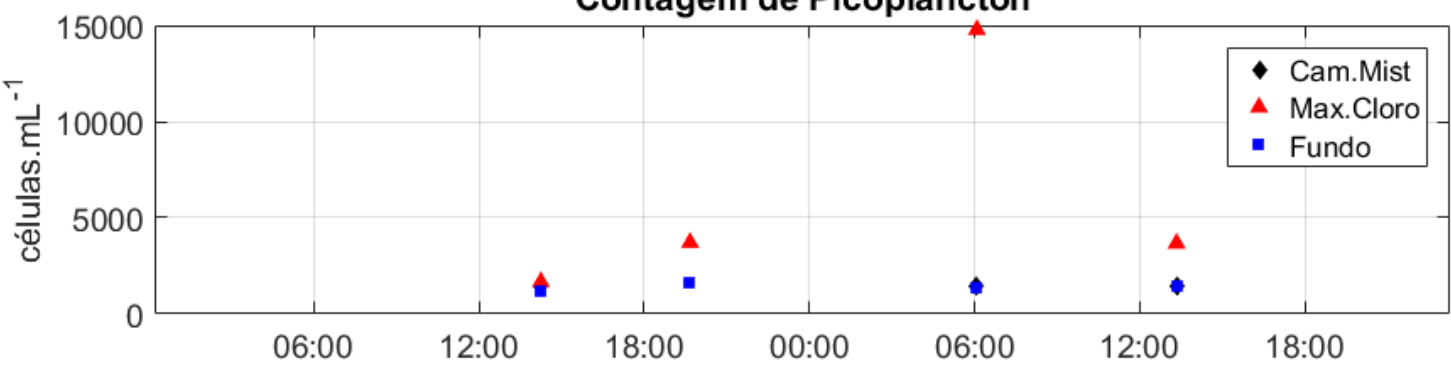

Figura 12: Variação temporal da densidade celular do nanoplâncton, picoplâncton eucarioto e procarioto dominado por Synechococcus spp. na Camada de Mistura, Máximo de Clorofila e Fundo, sobre a isóbata de 100 metros ao largo de Ubatuba-SP entre 12 e 13 de abril de 2015.

O gênero Synechococcus spp. foi numericamente mais abundante na maioria das amostras, representando cerca de 50\% do total de células do fitoplâncton. A densidade variou entre 2.500 e 14.000 células.mL ${ }^{-1}$. Na camada de mistura ultrapassou 10.000 células. $\mathrm{mL}^{-1}$ na manhã do segundo dia, mas se manteve abaixo de 5.000 células. $\mathrm{mL}^{-1}$ no restante do período amostrado. No MSC a densidade foi maior que nas demais profundidades com valores entre 5.000 e 14.000 células.mL ${ }^{-1}$. Os menores valores abaixo de 2.500 células. $\mathrm{mL}^{-1}$ foram registrados nas amostras de fundo. 
A concentração do picoplâncton variou entre 1.000 e 14.000 células.mL ${ }^{-1}$. O valor máximo foi observado as 6 horas da manhã do segundo dia na profundidade do MSC. Na camada de mistura e abaixo da termoclina o número de indivíduos permaneceu em torno de 1.000 células.mL ${ }^{-1}$ variando pouco ao longo do tempo.

O nanoplâncton foi o menos abundante em número de organismos, mas foi a população que melhor acompanhou a distribuição de clorofila ao longo do tempo. A densidade variou entre 400 e 2.000 células. $\mathrm{mL}^{-1}$ na coluna de água. Na camada de mistura, os valores variaram entre 800 e 1.100 células.mL ${ }^{-1}$. Nas amostras do MSC foram observados os maiores valores, variando entre 1.000 e 2.000 células. $\mathrm{mL}^{-1}$. No fundo, a concentração foi abaixo de 800 células. $\mathrm{mL}^{-1}$ em todo o período amostrado com pouca variação ao longo do tempo, e com densidades mínimas em torno de 400 células.mL $^{-1}$ observado na manhã do segundo dia.

\subsection{Curvas de luz fotossíntese e parâmetros fotossintéticos}

Os experimentos das curvas de luz fotossíntese das amostras 3 e 5 do MSC não saturaram o aparato fotossintético da comunidade presente. Com isso a taxa máxima de assimilação de carbono dessas amostras não foi atingida, resultando em um grande erro nos parâmetros obtidos (figura 13c e 14a). Nas demais amostras dos MSC, os valores

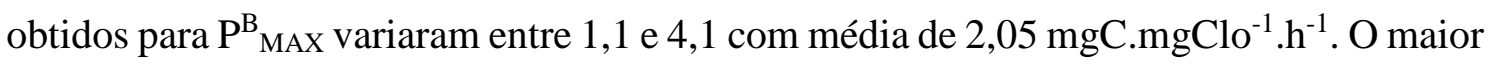
valor de $\mathrm{P}^{\mathrm{B}}$ MAX foi observado na primeira amostra do MSC. A inclinação inicial da curva de luz fotossíntese $(\alpha)$ variou entre 0,036 e $0,056 \mathrm{mg}$.C.mg.Clo ${ }^{-1} \cdot \mathrm{h}^{-1} \cdot \mu \mathrm{E} \cdot \mathrm{m}^{-2} \cdot \mathrm{s}^{-1} \mathrm{com}$ média de 0,043 . O maior valor de $\alpha$ foi observado na segunda amostra do MSC (figura 13b). 

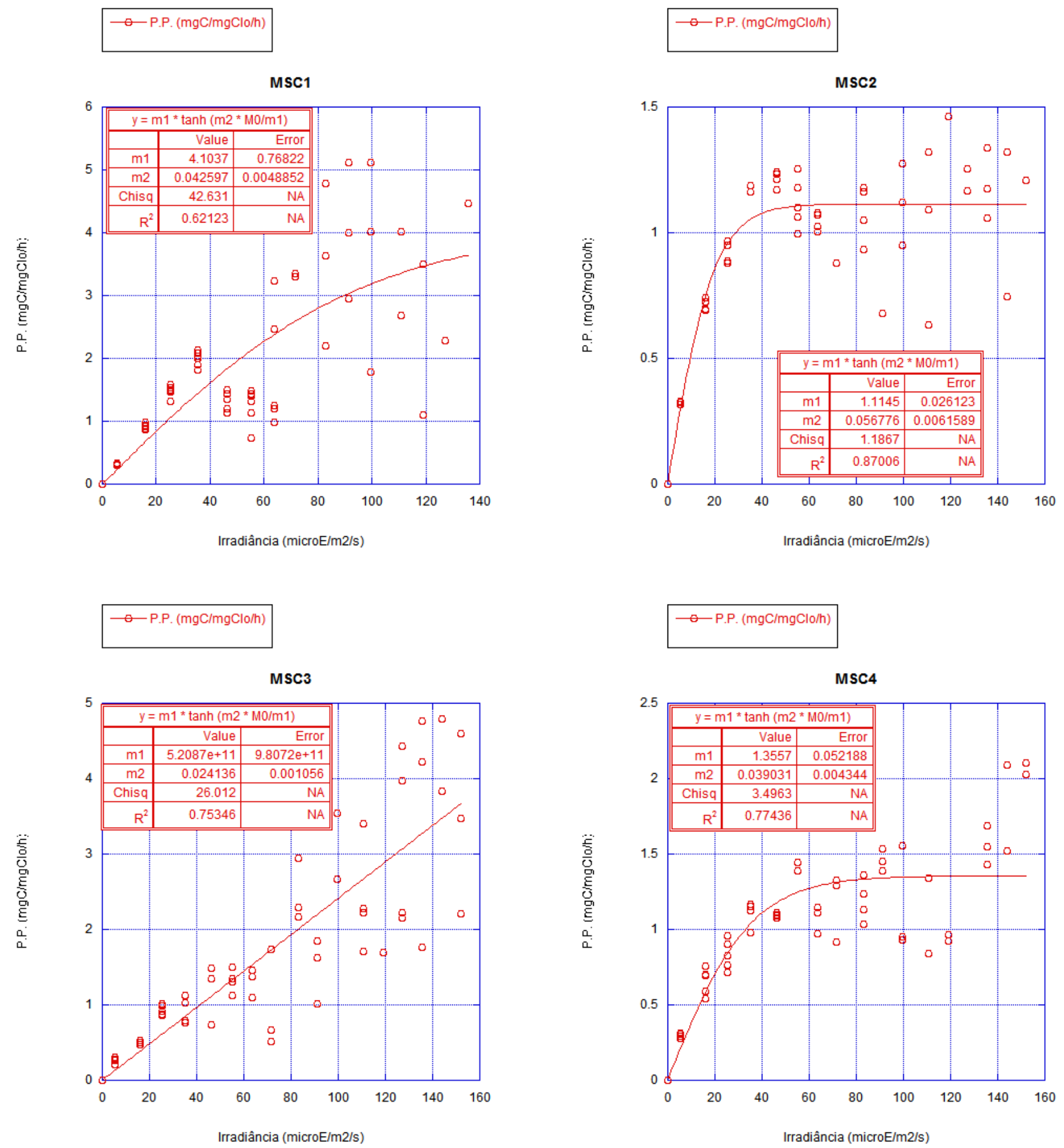

Figura 13: Curvas de Luz $\left(\mu \mathrm{E} . \mathrm{m}^{-2} . \mathrm{s}^{-1}\right)$ versus Fotossíntese e parâmetros fotossintéticos (tabela vermelha) dos máximos de clorofila (DCM1, DCM2, DCM3 e DCM4) amostrados na isóbata de 100 metros ao largo de Ubatuba-SP entre 12 e 13 de abril de 2015. 


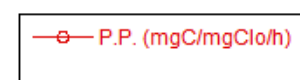

MSC5

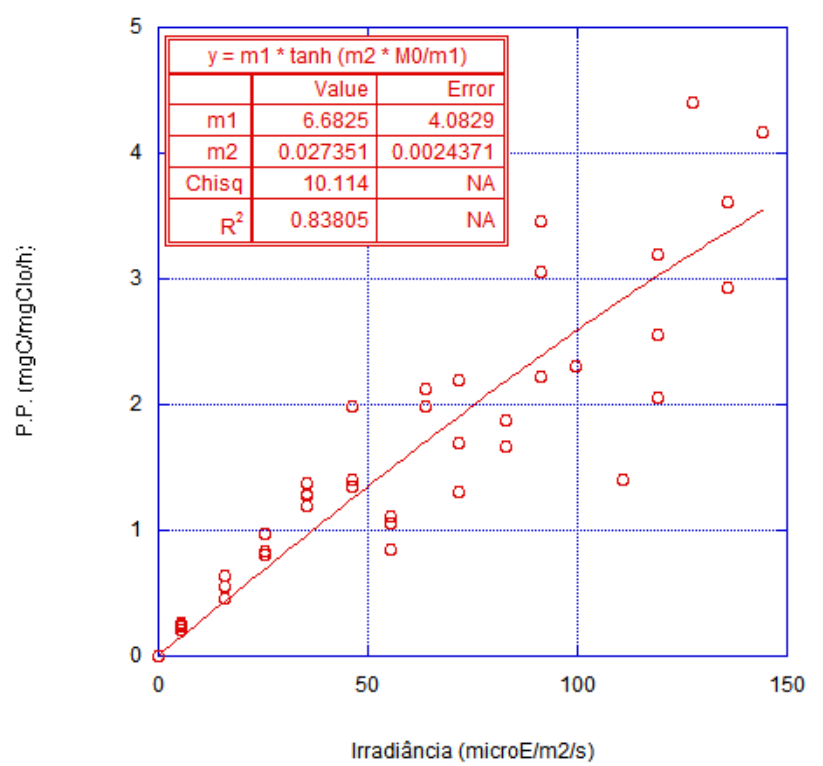

- P.P. (mgC/mgClo/h)

MSC6

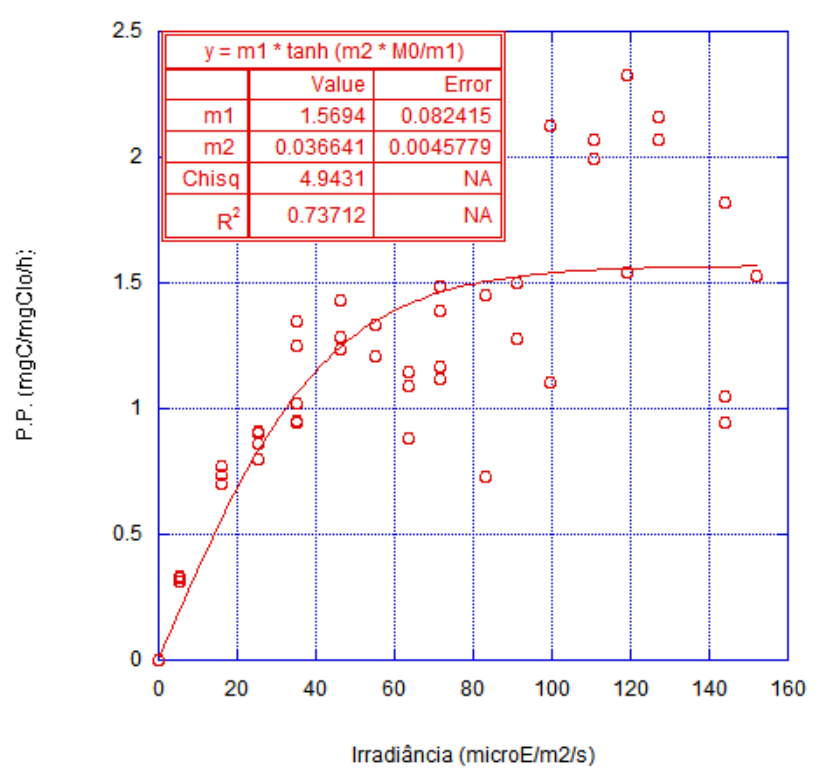

Figura 14: Curvas de Luz $\left(\mu \mathrm{E} \cdot \mathrm{m}^{-2} . \mathrm{s}^{-1}\right)$ versus transporte de elétrons e parâmetros fotossintéticos (tabela vermelha) dos máximos de clorofila (DCM5 e DCM6) amostrados na isóbata de 100 metros ao largo de Ubatuba-SP entre 12 e 13 de abril de 2015.

\subsection{Nível do mar}

O nível do mar registrado em Ubatuba variou entre 2000 e 2800 mm em uma semana em que a fase da lua era de quadratura (quarto minguante). A maré cheia ocorreu ao meio dia do primeiro dia e se repetiu com um período de aproximadamente 12 horas. Na figura 20, observa-se o "plot" da profundidade da isoterma de $19^{\circ} \mathrm{C}$ junto com a altura do nível do mar. O movimento vertical da isoterma acompanhou a variação do nível do mar, divergindo em apenas em alguns momentos como às 11 horas do primeiro dia e 16 horas do segundo dia (figura 15).

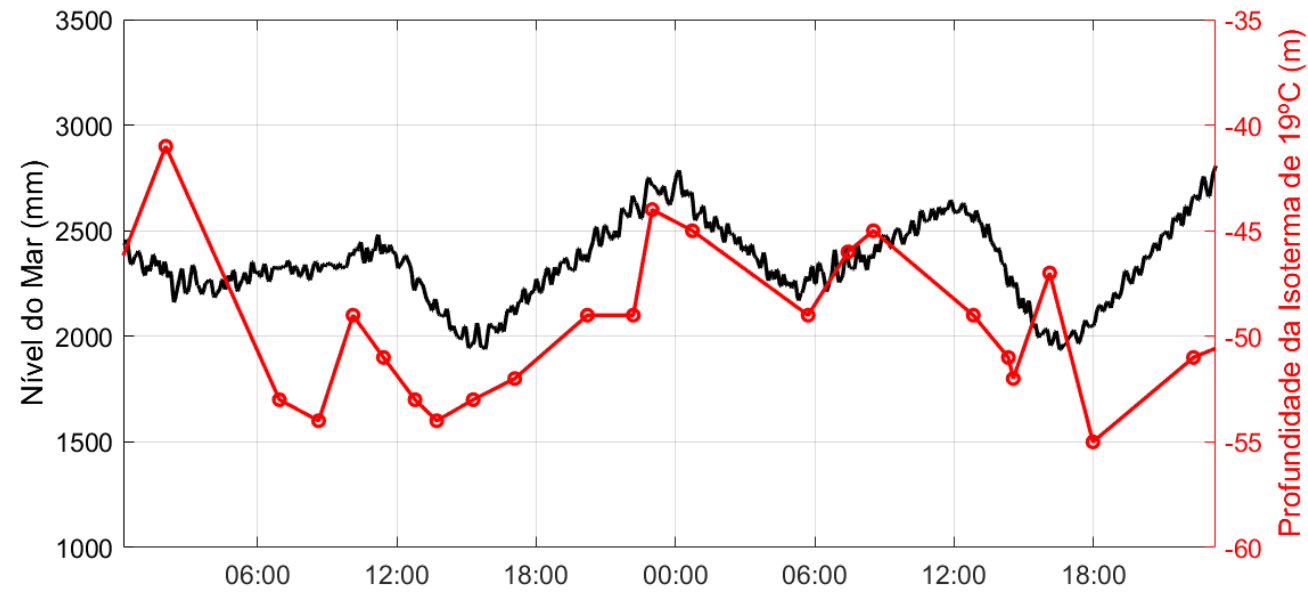

Figura 15: Séries temporais de altura do nível do mar e profundidade da isoterma de $19^{\circ} \mathrm{C}$ entre 12 e 13 de abril de 2015. 


\subsection{Qualidade espectral}

Os dados de qualidade espectral do Projeto Antares mostraram que o espectro da luz artificial utilizada nos experimentos compreende menos da metade da irradiância incidente no ambiente, sendo responsável em média por 38\% da RFA. Este valor foi utilizado para estimar a intensidade da luz azul incidente ao longo da coluna de água e subsequentemente nos cálculos de produção primária ao longo do tempo (figura 16).

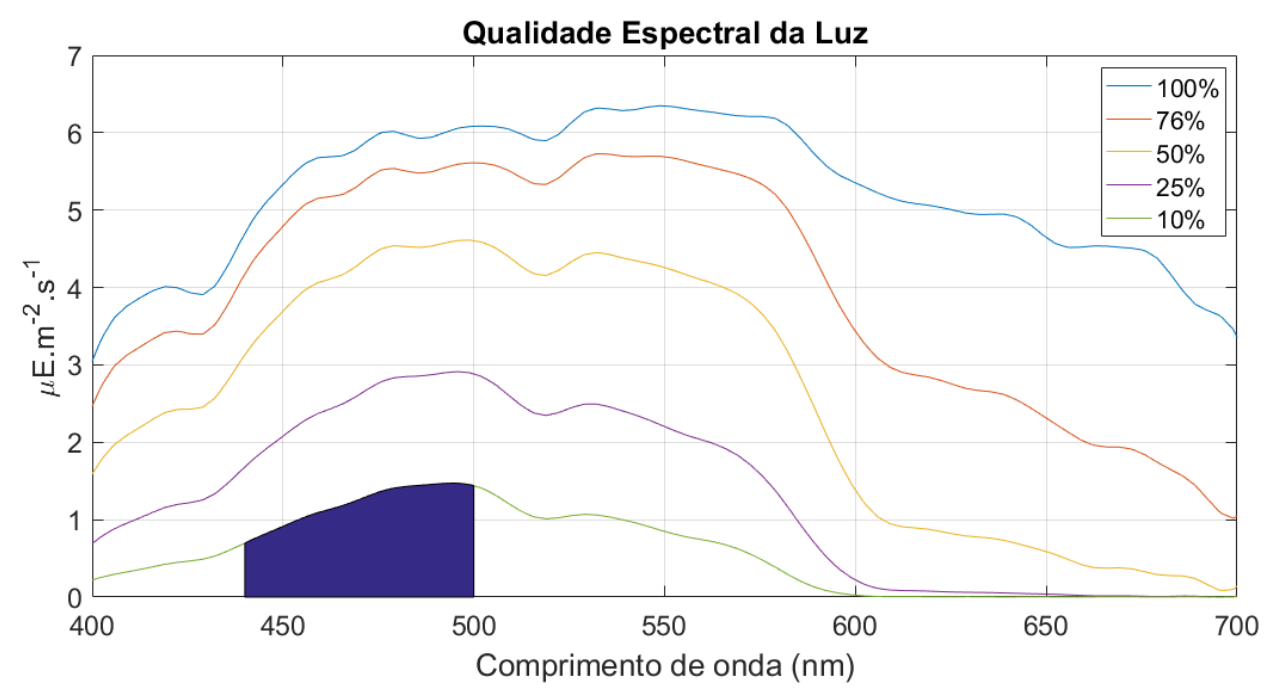

Figura 16: Qualidade espectral da luz incidente na coluna de água nas profundidades relativas a $100 \%, 75 \%, 50 \%, 25 \%$ e $10 \%$ da irradiância em superfície. Dados do projeto ANTARES, obtidos na isóbata de 40 metros ao largo de Ubatuba em maio de 2012.

\subsection{Irradiância incidente}

A RFA incidente na superfície atingiu valores próximos de $1500 \mu \mathrm{E} \cdot \mathrm{m}^{-2} \cdot \mathrm{s}^{-1}$ na metade dos dois dias. No primeiro dia praticamente acompanhou uma curva gaussiana entre o nascer e o pôr-do-sol, apenas com uma passagem de nuvens às 9 horas da manhã. No segundo dia o céu esteve coberto com nuvens praticamente o dia todo. Um pico de $1500 \mu \mathrm{E} \cdot \mathrm{m}^{-2} . \mathrm{s}^{-1}$ ocorreu ao meio dia, mas durou poucos minutos (figura 17 ). 


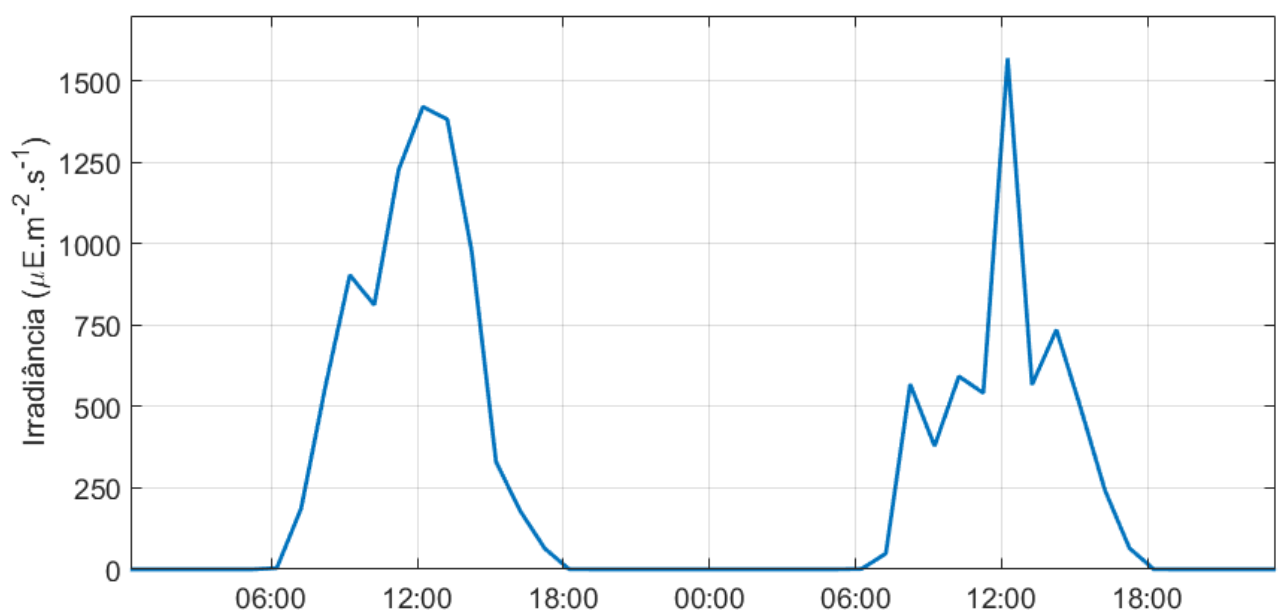

Figura 17: Radiação Fotossinteticamente Ativa incidente em Ubatuba entre os dias 12 e 13 de abril de 2015.

. Com base no coeficiente de extinção da luz $(k)$ estimado em 0,05 $\left(\mathrm{m}^{-1}\right)$ com base nos dados do sensor MODIS/AQUA, a espessura da zona eufótica foi estimada entorno de 90 metros. A radiação solar na profundidade da isoterma de $19^{\circ} \mathrm{C}$ manteve-se entre 5 e $10 \%$ da luz incidente na superfície, atingindo valores acima de $25 \mu \mathrm{E} \cdot \mathrm{m}^{-2} . \mathrm{s}^{-1}$ em grande parte do fotoperíodo do primeiro dia, mas apenas por poucas horas no segundo dia devido a passagem de nuvens (figura 18).

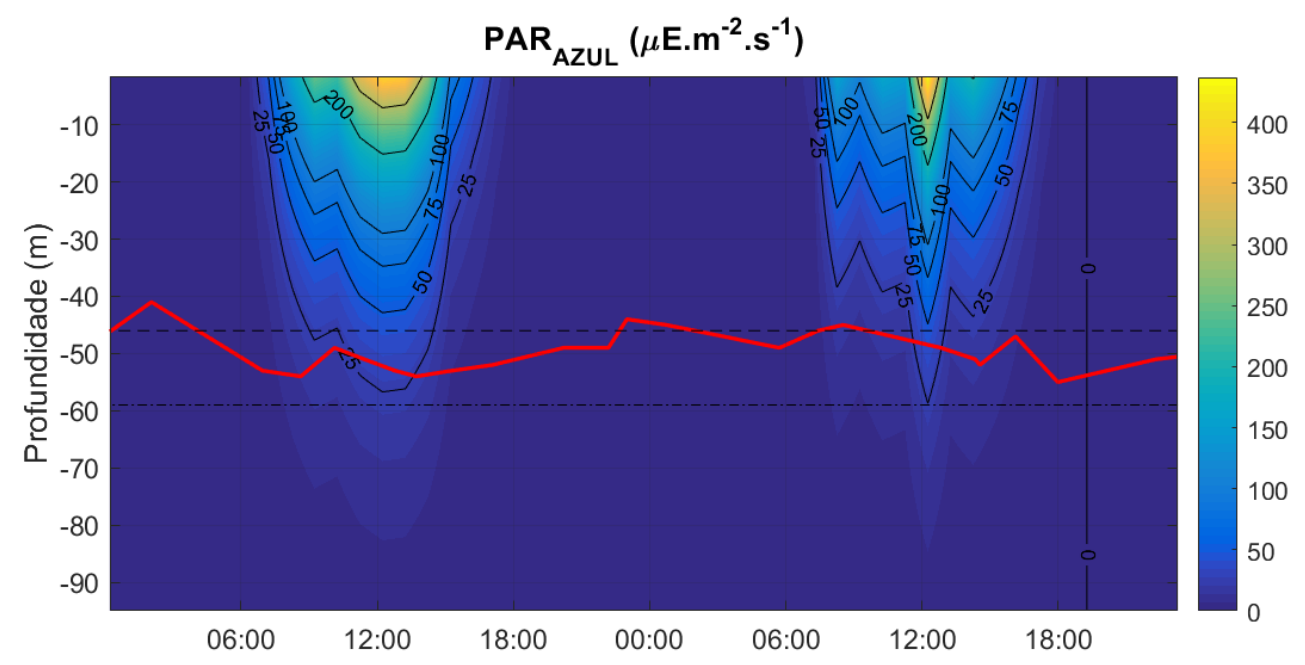

Figura 18: Intensidade da irradiância entre 440 e $500 \mathrm{~nm}$, incidente na coluna de água na isóbata de 100 metros ao largo de Ubatuba entre 12 e 13 de abril de 2015.

\subsection{Produção primária}

As taxas de assimilação de carbono variaram entre 0 e $1,2 \mathrm{mgC} \cdot \mathrm{m}^{-3} \cdot \mathrm{h}^{-1}$. Os maiores valores foram obtidos nas profundidades relativas aos MSC no meio dos dois dias, 
momentos em que a irradiância solar foi a máxima observada. Acima dos 40 metros de profundidade, as taxas não ultrapassaram $0,2 \mathrm{mgC} \cdot \mathrm{m}^{-3} \cdot \mathrm{h}^{-1}$. A partir dos 75 metros, a assimilação de carbono foi praticamente nula ao longo dos dois dias (figura 19).

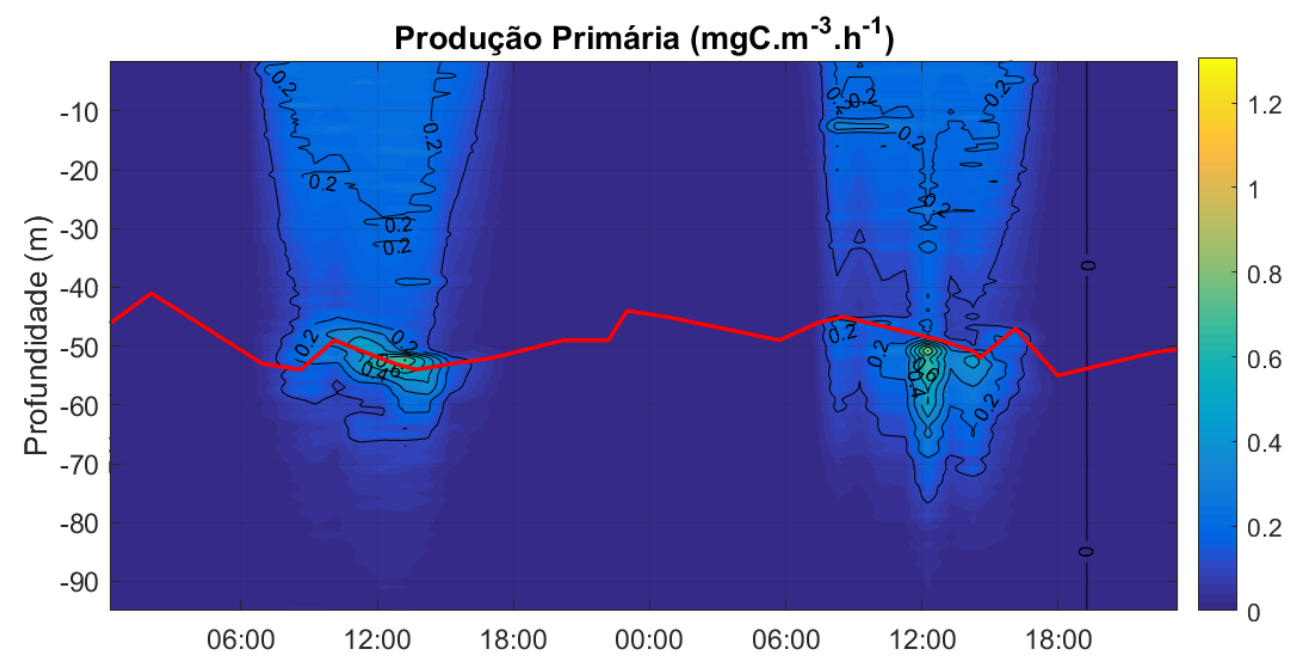

Figura 19: Estimativa da produção primária modelada com base na luz incidente ao longo da coluna de água sobre a isóbata de 100 metros em Ubatuba, entre 12 e 13 de abril de 2015.

A produção primária diária na zona eufótica estimada em função da fração azul da irradiância incidente foi de 112,5 e 111,3 mgC.m ${ }^{-2} \cdot \mathrm{d}^{-1}$ no primeiro e segundo dia respectivamente (tabela 2). A fração da coluna de água entre 40 e 60 metros de profundidade contribuiu significativamente para a produção da zona eufótica, sendo responsável por cerca de 30\% da produção nos dois dias.

Tabela 2: Valores de Produção Primária integrados $\left(\mathrm{mgC} \cdot \mathrm{m}^{-2} \cdot \mathrm{d}^{-1}\right)$ na Zona Eufótica e nos MSC observados entre 12 e 13 de abril de 2015 ao largo de Ubatuba.

\begin{tabular}{|c|c|c|}
\hline Prod. Prim. Integrada & Dia 1 & Dia 2 \\
\hline $0 m-Z_{\text {Eufótica }}$ & 112.5 & 111.3 \\
\hline $\mathrm{MSC}_{(40 \mathrm{~m}-60 \mathrm{~m})}$ & 34.6 & 33.6 \\
\hline MSC/PP.Z $Z_{\text {Eufótica }}$ & $31 \%$ & $30 \%$ \\
\hline
\end{tabular}

\section{Discussão}

Vale ressaltar que os resultados aqui obtidos podem ter sido parcialmente alterados devido a limitações metodológicas. O FRRf MK2 usado para se estimar o fluxo de elétrons e, indiretamente, as taxas de conversão de carbono inorgânico em carbono orgânico particulado, tem apenas um LED com um único pico de emissão no espectro do azul. Isso pode sem dúvida limitar o espectro de ação da fotossíntese (SIMIS et al., 2012). 
Algumas espécies de microalgas possuem uma composição pigmentar voltada para absorção de luz em outras regiões do espectro de luz, como verificado em cianobactérias com a luz verde (RAATEOJA et al., 2004 SCHREIBER et al., 2012; SILSBE \& KROMKAMP, 2012). Esta diferença pode ser responsável pela ineficiência da luz azul em saturar as amostras do MSC 3 e 5 . Nestas, a concentração de clorofila-a, nutrientes dissolvidos e a contagem de células do nanoplâncton foram abaixo do esperado para o máximo de clorofila-a, com valores muito próximos aos das amostras de superfície. A coleta desta amostra parece ter sido em profundidades da camada de mistura acima dos MSC. Além disso, a sensibilidade do citômetro de fluxo utilizado nas análises da densidade celular pode não ter sido capaz de quantificar a população de cianobactérias do gênero Proclorococcus spp., reconhecida como codominante com o Synechococcus em águas oligotróficas da plataforma externa. Ribeiro et al.. (2016) estudaram essas populações na mesma região e revelaram que o equipamento aqui utilizado pode ser preciso apenas em amostras coletadas abaixo dos 70 metros de profundidade devido ao aumento da concentração intracelular de clorofila como mecanismo de fotoadaptação.

Os cálculos de densidade celular por citometria de fluxo baseiam-se na fluorescência da clorofila-a que varia de espécie para espécie, em função do estado fisiológico e da irradiância incidente. Roesler et al. (2014) comparam estimativas horárias baseadas em medidas de fluorescência e também absorção de luz. A fluorescência tende a diminuir em irradiâncias a cima de $100 \mu \mathrm{E} \cdot \mathrm{m}^{-2} \cdot \mathrm{s}^{-1}$. Considerando apenas a porção azul do espectro do visível considerado neste trabalho, irradiâncias acima de $30 \mu \mathrm{E} \cdot \mathrm{m}^{-2} . \mathrm{s}^{-1}$ podem ativar os fotossistemas e iniciar a fotossíntese. Portanto, as estimativas da biomassa fitoplanctônica “in situ” no fotoperíodo podem estar sub-estimadas. Foi evidente o acúmulo de clorofila na zona eufótica no final do período diurno. A qualidade espectral ao longo da profundidade não foi medida e as estimativas de produção da camada de mistura através da modelagem podem ter sido subestimadas. De qualquer forma tendo em vista que os comprimentos de onda predominantes nos níveis subsuperficiais, onde ocorrem os MSC, são os da luz azul essas interferências devem ter afetado apenas parcialmente os resultados de fotossíntese obtidos sem, no entanto, comprometer a resposta às variações de luz nos níveis onde ela é limitante.

Os resultados desse trabalho corroboram com os observados em diversos trabalhos feitos na para a região (BRANDINI, 1990; AIDAR et al., 1993; GAETA \& BRANDINI, 2006; BRANDINI, 2003; CASTRO et al., 2006) os quais revelam um cenário 
hidrográfico dominado por uma coluna de água fisicamente estratificada e três biótipos verticais: (i) o da camada superficial de mistura cuja produção nova (sensu DUGDALE \& GOERING, 1967) é limitada por macronutrientes, sobretudo nitrato (AIDAR et al., 1993), e baixas concentrações de clorofila-a (ii) o da camada de fundo, com águas frias e ricas em nutrientes típicas da ACAS e limitada por luz, e (iii) o dos níveis intermediários na base da zona eufótica, onde a presença da ACAS reduz a limitação por nutrientes novos e favorece o desenvolvimento e acúmulo de uma comunidade fitoplanctônica adaptada à baixas intensidades de luz, e geralmente dominados por diatomáceas do nano e do microplâncton representantes de um sistema de produção nova (BRANDINI et al., 2013). São várias as evidências de que os MSC da região sudeste do Brasil são formados pelo acúmulo de diatomáceas fotoadaptadas a baixas intensidades de luz e nutridas pelas altas concentrações de nitrato devido a presença da ACAS no fundo (BRANDINI et al., 2013). Os resultados desse trabalho também indicam que o MSC contribuiu com cerca de 30\% da produção da zona eufótica sobre a isóbata de 100 metros.

Metzler et al. (1997) estudaram a contribuição da produção nova e regenerada em regiões oceânicas e na plataforma interna ao largo de Ubatuba com experimentos de assimilação de ${ }^{15} \mathrm{~N}$. Em condições de estratificação da coluna de água na região oceânica a comunidade do $1 \%$ de luz apresentou elevados valores de assimilação de nitrato associados a presença da ACAS, predominando a produção nova (76\% da produção total) em relação a regenerada em profundidades enriquecidas por essa massa de água. Na camada de mistura (50\% de luz), os autores observaram predomínio da produção regenerada (>90\% da produção total). Brandini et al. (2013) observaram predomínio de pequenos flagelados na camada de mistura, corroborando com os resultados de Metzler et al. (1997) uma vez que esse grupo de organismos possui baixa demanda de nutrientes e predomina em ambientes oligotróficos.

Apesar do presente estudo não ter analisado a composição dos MSC por microscopia, a citometria de fluxo forneceu um panorama geral das frações de tamanho dominantes do pico- e dos nano eucariotos autotróficos. O número total desses organismos das amostras de MSC foi em média maior do que nas demais profundidades, sendo que o nanoplâncton foi o que melhor correlacionou positivamente com a variação de clorofila-a nesses níveis da coluna de água. Possivelmente ambas as frações do nanoe do microplâncton eucarioto dividem a contribuição para a produção nova total nos níveis subsuperficiais da zona eufótica da plataforma continental sudeste. 
Trabalhos realizados em outras regiões mostram que a dissipação de energia devido a quebra de ondas internas pode aumentar em até 4 vezes a concentração de nitrato e em cerca de 40\% a clorofila-a na camada de mistura (CULLEN et al., 1983; SANDSTROM \& ELLIOT, 1984; CASTRO et al., 2002; SANGRÀ et al., 2001). A quebra das ondas internas depende da profundidade da termoclina e da profundidade local. Uma vez que a barreira física que mantinha a termoclina é rompida, a água da coluna inteira se mistura e fertiliza a camada eufótica acima, gerando um efeito positivo nas taxas de fotossíntese e, consequentemente, na produção primária integrada. No entanto, nesse trabalho não foram observadas variações significativas nas concentrações dos nutrientes dissolvidos na camada de mistura. As concentrações de nitrato na camada de mistura permaneceram a baixo de $0,4 \mu \mathrm{M}$ com valores de clorofila em torno de 0,1 mg. $\mathrm{m}^{-3}$ ao longo do período amostrado.

Portanto, os resultados sugerem que as variações das taxas de fotossíntese obtidas ao longo da coluna de água foram mais afetadas por variações na intensidade de luz devido aos deslocamentos verticais do fitoplâncton provocados por onda interna do que por aumentos na concentração de nutrientes. De fato nos níveis nos quais a luz é limitante da produção primária, pequenas variações na irradiância in situ ao longo do fotoperíodo podem afetar substancialmente as taxas de fotossíntese, aumentando momentaneamente a produção primária integrada na zona eufótica, sobretudo em se tratando de comunidades dominadas por células pequenas com maior eficiência na absorção de luz devido a maior relação superfície:volume (MARAÑÓN, 2014).

Lande e Yentsch (1988) buscaram quantificar o efeito de ondas internas na produção primária devido a variações na irradiância incidente nos MSC a partir de uma relação entre o coeficiente de extinção da luz e a amplitude de oscilação de isopicnais. Os autores argumentam que os movimentos verticais podem aumentar a intensidade de luz entre 8 e 20\% em águas oligotróficas durante poucas horas e, consequentemente, estimativas de produção primária a partir de incubações de amostras obtidas discretamente na coluna de água podem estar subestimadas em até 20\%. Evans et al. (2008) estudaram o efeito de ondas internas a partir de experimentos in situ e de modelos matemáticos, revelando que variações da irradiância em superfície devido a passagem de nuvens podem interagir com cristas e cavados de ondas internas gerando efeitos negativos ou positivos, dependendo da fase relativa entre os movimentos verticais e o ciclo do sol diário. A comunidade fitoplanctônica pode ser advectada na coluna de água para cima na 
crista da onda interna, recebendo mais luz no período diurno e, consequentemente, aumentar em $200 \%$ as taxas fotossintéticas. Por outro lado, essa mesma comunidade em questão de horas pode ser deslocada para baixo no cavado da onda interna, onde a intensidade luminosa é ainda menor, aumentando ainda mais a limitação pela luz e nesse caso a produtividade de comunidades subsuperficiais pode ser reduzida em cerca de $15 \%$. Em resumo, os deslocamentos verticais dos MSCs podem gerar um efeito tanto positivo quanto negativo, dependendo da hora do dia, da variação na cobertura de nuvens, do coeficiente de extinção de luz da água e da amplitude da onda.

A partir dos resultados obtidos no presente estudo, os efeitos de ondas internas em um determinado nível dos MSC podem também ser comprovados através do modelo ilustrado na figura 20. A passagem de cristas pode elevar a irradiância incidente em 1,5 vezes e consequentemente aumentar em $24 \%$ a assimilação de Carbono momentaneamente. Considerando o mesmo perfil de luz, mas em uma condição com passagem de cavas de ondas internas, a variação na luminosidade dos MSCs é de cerca de $-25 \%$, podendo reduzir a atividade fotossintética em $20 \%$.
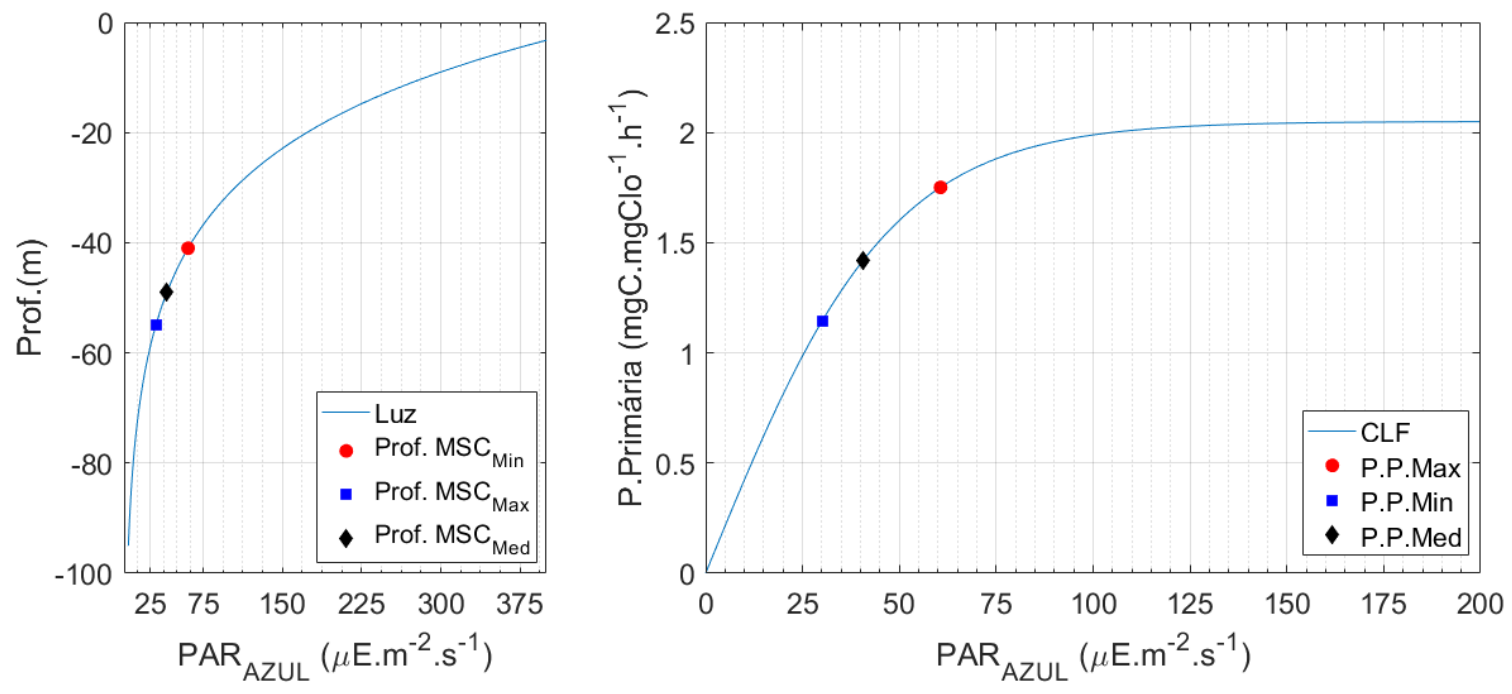

Figura 20: (a) Irradiância solar ao longo da coluna de água e (b) Curva de Luz versus Fotossíntese ilustrando variações na profundidade e nas taxas fotossintéticas do máximo sub-superficial devido passagem de ondas internas.

\section{Conclusão}

Os resultados desse trabalho respondem aos objetivos da seguinte maneira: Não houve indícios de enriquecimento da zona eufótica com nutrientes da ACAS em função 
da passagem de ondas internas, revelando que o aumento da produção primária integrada na zona eufótica está mais relacionada com a redução da limitação por luz nos níveis da base da zona eufótica. A maior disponibilidade de luz ocorre em períodos diurnos que coincidam com o deslocamento dos MSC durante a passagem da crista da onda. Ondas internas com grandes períodos e em fase com a variação diurna da irradiância solar podem, portanto, contribuir significativamente para o aumento da produção nova dos MSC distribuídos na PSCE que nesse trabalho estimou em 30\% a contribuição desses máximos para a produção integrada sobre a isóbata de 100 metros. Mais dados são necessários em diferentes isóbatas de modo a se obter uma estimativa geograficamente mais representativa do papel das ondas internas na produção primária da plataforma continental da região sueste de Brasil.

\section{Referências bibliográficas}

AIDAR, E., GAETA, S. A., GIANESELlA-GALVÃO, S. M. F., KUTNER, B., TEIXEIRA, C. 1993. "Ecossistema costeiro subtropical: nutrientes dissolvidos, fitoplâncton e clorofila-a e suas relações com as condições oceanográficas na região de Ubatuba, SP”. Publicação esp. Inst. Oceanogr., São Paulo, (10):9-43.

ÁlVAREZ BORREGO, S.; NÁJERA MARTÍNEZ, S.; ZIRINO, A. R.; GAXIOLA CASTRO, G. 2002. "Efecto de las ondas internas en el fitoplancton del Golfo de California”. Ciencias Marinas, septiembre, 297-309.

APEL, J. R.; HOLBROOK, J. R.; LIU, A. K.; TSAI, J. J. 1985. “The Sulu sea internal soliton experiment,”. Journal of Physical Oceanography, vol. 15, no. 12, pp. 1625-1651.

BRANDINI, F. P. 1988. “Composição e Distribuição do Fitoplâncton na Região Sueste do Brasil e Suas Relações com as Massas de Água (Operação Sueste Julho/Agosto 1982)”. Ciência e Cultura, 40(4): 334 - 341.

BRANDINI, F. P.; MORAES, C. L. B.; THAMM, C. A. C. 1989. "Shelf-break upwelling, subsurface maxima of chlorophyll and nitrite, and vertical distribution of a subtropical nano-microplankton community off southeastern Brazil”. Memórias do III Encontro Brasileiro de Plâncton (F.P Brandini, coord.), Curitiba, p.47-55.

BRANDINI, F. P. 1990. "Produção primária e caracteristicas fotossintéticas do fitoplâncton na região sueste do Brasil”. Bolm Inst. Oceanogr., São Paulo, 38(2):147-159. 
BRANDINI, F. P.; NOGUEIRA, M.; SIMIÃO, M.; CODINA, J. C. U.; NOERNBERG, M. A. 2013. “Deep chlorophyll maximum and plankton community response to oceanic bottom intrusions on the continental shelf in the South Brazilian Bight”. Continental Shelf Research, Online publication date: 1-Sep-2013.

CARPENTER, E. J.; CAPONE, D. G. 1983. "Nitrogen in the Marine Environment”. New York, Academic Press.

CASTRO FILHO, B. D., MIRANDA, L. D., \& MIYAO, S. Y. 1987. "Condições hidrográficas na plataforma continental ao largo de Ubatuba: variações sazonais e em média escala”. Boletim do Instituto Oceanográfico, 35(2), 135-151.

CASTRO, B. M. 1996. “Correntes e Massas de Água da Plataforma Continental Norte de São Paulo”. Tese de Livre Docência. Instituto Oceanográfico da Universidade de São Paulo, 248p.

CASTRO, B. M.; LORENZZETTI, J. A.; DA SILVEIRA, I.C.A \& MIRANDA, L.B. 2006. Estrutura termohalina e circulação na região entre o Cabo de São Tomé (RJ) e o Chuí (RS). In: ROSSI-WONGTSCHOWSKI, C. L. B.; MADUREIRA, L. S. P. (Eds.). . O Ambiente Oceanográfico da Plataforma Continental e do Talude na Região SudesteSul do Brasil. São Paulo: Edusp, p. 11-120.

CERDA, C.\& CASTRO, B. M. 2014. Hydrographic climatology of South Brazil Bight shelf waters between Sao Sebastião $\left(24^{\circ} \mathrm{S}\right)$ and Cabo Sao Tome (22 $\left.{ }^{\circ} \mathrm{S}\right)$. Cont.Shelf Res., v. 89, p. 5-14.

CHUQUI, M. G. 2013. “Estudo da produtividade primária fitoplanctônica em uma estação fixa na região da plataforma interna de Ubatuba (SP)”. Trabalho de Graduação. Instituto Oceanográfico da Universidade de São Paulo.

CULLEN, J.J.; STUART, E.; RENGER, E.; EPPLEY, R.W.; WINANT, C.D. 1983. "Vertical motion of the thermocline, nitracline and chlorophyll maximum layers in relation to currents on the Southern California Shelf”. Mar. Res., 41, 239-262.

DIAS, F. G.; LORENZZETTI, J. A. 2013. “Internal Solitary Waves in the Brazilian SE Continental Shelf: Observations by Synthetic Aperture Radar,” International Journal of Oceanography, vol. 2013, Article ID 403259, 11 pág. 
DUGDALE, R. C.; GOERING, J. J. 1967. “Uptake of New and Regenerated Forms of Nitrogen in Primary Productivity”. Limnology and Oceanography, 12: 196-206.

DYCK, A. \& SUMAILA, U. 2010. “Economic impact of global fish populations in the global fishery”. J. Bioecon., v. 12, n. 3, p. 227-243.

GAETA, S. A. 1999. "Produção Primária na Região Oeste do Atlântico Sul”. Tese de Livre Docência. Instituto Oceanográfico da Universidade de São Paulo, 140p.

GAETA, S. A.; S. M. S. Ribeiro; P.M. Metzler; M. S. Francos; D. S. Abe, 1999. "Environmental forcing on phytoplankton biomass and primary productivity of the coastal ecosystem in Ubatuba region, southern Brazil”. Rev. Bras. Oceanogr., Vol. 47(1):11-27.

GAETA, S. A.; BRANDINI, F. P. 2006. "Produção Primária do Fitoplâncton na Região entre o Cabo de São Tomé (RJ) e o Chuí (RS)”. In: Carmen Lucia Del Bianco Rossi-Wongtschowski; Lauro Saint-Pastous Madureira. (Org.). O Ambiente Oceanográfico da Plataforma Continental e do Talude na Região Sudeste-Sul do Brasil. 1a ed. São Paulo: EDUSP, p. 219-264.

GARRETT, C. J. R.; MUNK, W. H. 1979. “Internal waves in the oceans”. Annu. Rev. Fluid Mech., 11, 339-369.

GRASSHOFF, K. 1976. “Methods of Seawater Analysis”. Verlag Chemie, Second Edition.

HOLLOWAY, G. 1984. "Effects of velocity fluctuations on vertical distributions of phytoplankton”. J. Mar. Res., 42, 559-571.

HOLLOWAY, G.; DENMAN, K. 1989. "Influence of internal waves on primary production”. J. Plankton Res. 11: 409-413.

JAHNKE, R. A. 2010. “Global Synthesis. In: LIU, K.-K. et al. (Eds.). Carbon and nutrient fluxes in continental margins”. Berlim: Springer, 757p.

JASSBY, A. D.; PLATT, T. 1976. Mathematical formulation of the relationship between photosynthesis and light for phytoplankton. Limnology and oceanography, v. 21, n. 4, p. 540-547. 
KATSURAGAWA, M.; MATSUURA, Y.; SUZUKI, K.; DIAS, J. F.; SPACH, H. L. 1993. "O Ictioplancton ao Largo de Ubatuba, SP: Composição, Distribuição e Ocorrencia Sazonal (1985-1988)”. Publicação Esp. Inst. Oceanogr., São Paulo, (10):85121.

KIRK, J. 1983. "Light and photosynthesis in aquatic ecosystems”. Cambridge Univ. Press., Londres, Nova York, New Rochelle, Melbourne, Sydney. 399p.

LEE, LANDE, R.; YENTSCH, C. S. 1988. “Internal waves, primary production and the compensation depth of marine-phyto- plankton”. J. Plankton Res. 10: 565-571.

LIU, C.T.; PINKEL, R.; HSU, M.K.; KLYMAK, J.M.; CHIEN, H.W.; VILLANOY, C. 2006. “Nonlinear internal waves from the Luzon Strait”. Eos Trans AGU 87(42):449-451.

LONGHURST, A. R. 1991. "Role of the marine biosphere in the global carbon cycle”. Limnol Oceanogr. 36:1507-1526.

MANN, K. H.; LAZIER, J. R. N. 2006. "Vertical structure of the open ocean: biology of the mixed layer”. Dynamics of Marine Ecosystems, Third Edition, p. 68-117.

MARAÑÓN, E., 2015. “Cell size as a key determinant of phytoplankton metabolism and community structure”. Annual Review of Marine Science, 7: 241-264.

MARGALEF, R. 1978. Life-forms of phytoplankton as survival alternatives in an unstable environment. Oceanologica acta, v. 1, n. 4, p. 493-509.

MARIE, D.; SIMON, N. e VAULOT, D. 2004. Phytoplankton cell counting by flow cytometry. Algal culturing techniques, v. 1, p. 253-267.

MATSUURA, Y. 1986. Contribuição ao estudo da estrutura oceanográfica da região sudeste entre Cabo Frio (RJ) e Cabo de Santa Marta Grande (SC). Ciência e Cultura, 38(8): 1439-1450.

MESQUITA, A.R.; LEITE, J.B.A.; RIZZO, R. 1993. "Note on the shelfbreak upwelling off the southeast coast off Brazil (Lat. 26³0'S)”. Bolm. Inst. oceanogr., São Paulo, 32: 193-198.

METZLER, P M. 1991. "Estudo da produtividade primária e características fisiológicas do fitoplâncton na região de Ubatuba, São Paulo, através de curvas de luz- 
fotossíntese”. Dissertação de mestrado. Universidade de São Paulo, Instituto Oceanográfico. 208p.

METZLER, P.M.; GLIBERT, P.M.; GAETA, S.A.; LUBLAN, J. 1997. "New and regenerated production in the South Atlantic off Brazil”. Deep-Sea Res., 44: 363-384.

MIRANDA, L. B., 1982. “Analise de massas de água da plataforma continental e da região oceânica adjacente: Cabo de São Tome (RJ) a Ilha de São Sebastiao (SP) ”. Dissertacao de Livre-Docencia. Universidade de São Paulo.

PARANHOS, R. 1996. “Alguns métodos para análise da água”. Rio de Janeiro: Cadernos didáticos UFRJ, 200p.

PLATT, T., GALLEGOS, C. L. 1980. “Modelling primary production.”. In: FALKOWSKI, P. G., ed. Primary productivity in the sea. New York, Plenum Press. p. 339-362.

PAULY, D.; CHRISTENSEN, V.; GUÉNETTE, S.; PITCHER, T.J.; RASHID SUMALIA, U.; WALTERS, C.J.; WATSON, R. \& ZELLER, D. 2002. Towards sustainability in world fisheries. Nature, v. 418, n. 6898, p. 689-695.

PEREIRA, A. F.; CASTRO, B. M. 2007. “Internal Tides in the Southwestern Atlantic off Brazil: observations and numerical modeling”. Journal of Physical Oceanography, vol. 37, nº 6, pág. 1512-1526.

RAATEOJA, M.,SEPPALA, J.,YLOSTALO, P., 2004. "Fast repetition rate fluorometry is not applicable to studies of filamentous cyanobacteria from the Baltic Sea”. Limnol. Oceanogr. 49 (4), 1006-1012.

RIBEIRO, G. C.; SANTOS, L. A.; MARIE, D.; PELLIZARI, V. H.; BRANDINI, F. P., VAULOT, D. 2016. "Pico and nanoplankton abundance and carbon stocks along the Brazilian Bight”. PeerJ, 4, e2587.

ROESLER, C. S.; BARNARD, A. H. 2014. “Optical proxy for phytoplankton biomass in the absence of photophysiology: Rethinking the absorption line height”, Methods in Oceanography, Volume 7, September 2013, Pag. 79-94.

RYTHER, J. H. 1969. "Photosynthesis and fish production in the sea”. Science, 166:72-76. 
SALDANHA-CORREA, F.M.P. 1999. “Aspectos da variação vertical e temporal da produção primária e biomassa fitoplanctônica, em uma estação fixa na região costeira de São Sebastião (SP)”. Tese de Doutoramento. Instituto Oceanográfico da Universidade de São Paulo, 100p.

SANDSTROM, H.; ELLIOTT, J .A. 1984. "Internal tide and solitons on the Scotian Shelf, a nutrient pump at work”. Journal of Geophysical Research 89:6415- 6426.

SANGRÀ, P.; BASTERRETXEA, G.; PELEGRÍ, J.; ARÍSTEGUI, J. 2001. "Chlorophyll increase due to internal waves in the shelf-break of Gran Canaria Island (Canary Islands)”. Scientia Marina, 65(S1), 89-97.

SANTOS, P. P. G. M. 2012. "Estudo das variações sazonais da biomassa fitoplanctônica e dos nutrientes ao largo de Ubatuba, São Paulo, em resposta ao campo de ventos”. Trabalho de Graduação. Universidade de São Paulo, Instituto Oceanográfico. $55 p$.

SCHREIBER, U.,KLUGHAMMER, C., KOLBOWSKI, J., 2012. “Assessment of wavelength-dependent parameters of photosynthetic electron transport with a new type of multi-color PAM chlorophyll fluorometer”. Photosynth. Res. 113, 127-144.

SILSBE, G.M.,KROMKAMP, J.C., 2012. "Modelling the irradiance dependency of the quantum efficiency of photosynthesis”. Limnol. Oceanogr. Methods 10, 645-652

SILVEIRA, I. C. A., 2007. “O Sistema Corrente do Brasil na Baia de Campos, RJ”. Tese de Livre Docência. Universidade de São Paulo, São Paulo. 181 pp.

SIMIS, G.H., HUOT, Y., BABIN, M., SEPPALA, J., METSAMAA, L., 2012. “Optimization of variable fluorescence measurements of phytoplankton communities with cyanobacteria”. Photosynth. Res. 112, 13-30.

SIMPSON, J. H.; SHARPLER, J. 2012. "Introduction to the physical and biological oceanography of shelf seas”. Cambridge: Cambridge University Press, 2012.

STEEMAN-NIELSEN. 1952. "The use of radio-active carbon $\left({ }^{14} \mathrm{C}\right)$ for measuring organic production in the sea”. J. Cons. Int. Explor. Mer. 18,117-140.

TEIXEIRA, C. 1973a. "Introdução aos métodos para medir a produção primária do fitoplâncton marinho”. Bolm Inst. Oceanogr., São Paulo, 22:59-92. 
TEIXEIRA, C. 1973b. "Preliminary studies os primanry production in the Ubatuba region (Lat. 23³0’S Long. 4506’W) Brazil’. Bolm. Inst. oceanog., 22: 49-58.

TEIXEIRA, C. \& VIEIRA, A. A. H. 1976. "Nutrient experiment using Phaeodactilum tricomutum as an assay organism”. Bolm. Inst. oceanog., 25(1):29-42.

TEIXEIRA, C. \& TUNDISI, J. G. 1981. “The effects of nitrogen and phosphorus enrichment on phytoplankton in the region of Ubatuba (Lat. $23^{\circ} 30^{\prime}$ 'S Long. $45^{\circ} 06^{\prime} \mathrm{W}$ )”. Brasil. Bolm Inst. oceanog., S. Paulo. 30(1):77-86.

THIMIJAN, R. W.; HEINS, R. D. 1983. "Photometric, radiometric, and quantum light units of measure: a review of procedures for interconversion”. HortScience, v. 18, n. 6, p. 818-822.

WELSCHEMYER, N. A. 1994. "Fluorometric Analysis of Chlorophyll-a in the Presence of Chlorophyll-b and Pheopigments”. Limnol. Ocenogr., 39: 1985-1992.

WINKLER, L.S. 1888. “The Determination Of Dissolved Oxygen”. Ber. Dtsche. Chem. Ges. 21: 2843-2855.

ZEMBRUSKI, S. G., 1979. “Geomorfologia da margem continental brasileira e das áreas oceânicas adjacentes”. Série Projeto REMAC, vol. 7, pp. 129-174. 